\title{
EXAMINING THE PERFORMANCE GAP IN LEED CERTIFIED MURBS
}

\author{
by \\ Kaitlin Paige Carroll \\ Bachelor of Arts, University of Toronto, 2015
}

\author{
A Major Research Project \\ presented to Ryerson University \\ in partial fulfillment of the \\ requirements for the degree of \\ Master of Building Science \\ in the Program of \\ Building Science
}

Toronto, Ontario, Canada, 2018

(C) Kaitlin Paige Carroll 2018 


\section{AUTHOR'S DECLARATION FOR ELECTRONIC SUBMISSION OF A MRP}

I hereby declare that I am the sole author of this MRP. This is a true copy of the MRP, including any required final revisions.

I authorize Ryerson University to lend this MRP to other institutions or individuals for the purpose of scholarly research.

I further authorize Ryerson University to reproduce this MRP by photocopying or by other means, in total or in part, at the request of other institutions or individuals for the purpose of scholarly research.

I understand that my MRP may be made electronically available to the public. 
Examining the Performance Gap in LEED Certified MURBs

Kaitlin Paige Carroll, MBSc, 2018.

Master of Building Science,

Ryerson University

\section{Abstract}

This study assesses the performance gap between actual energy performance and desired energy performance outcomes for a case study of 19 LEED-certified multi-unit residential buildings in the Greater Toronto Area. The study examines 1) how accurately design-stage energy modelling predicts actual energy use, 2) how much variation of energy performance can be seen between buildings of the same level of certification, and 3) the key contributing factors of this performance gap. Using EUI as the basis of comparison, trend analysis was carried out. It was determined that a performance gap between modelled and actual building energy use does exist. When compared to a larger sample of existing buildings, the case study buildings show no real improvement, on average. Regression models revealed no strong correlation between LEED Level or LEED EAc1 credits and reduced EUls. 


\section{Acknowledgements}

I would like to express my sincere supervisor, Prof. Vera Straka for the continuous support of this major research project, and for her patience, motivation and immense knowledge without which this study would not have been possible.

Besides my adviser I would also like to recognize my second reader, Dr. Russell Richman, and thank him for the invaluable support and insightful feedback which allowed me to develop this project into its full form.

I would like to acknowledge EQ Building Performance, especially Craig McIntyre and Samantha Menard for making this study possible, providing the initial direction for this project, and thoughtful commentary throughout the process.

Last but not least, I would thank the entire Ryerson Building Science cohort, but especially Kelly Fordice, Ashley Lubyk, Deva Veylan, Austin Todd, and Felix Chen for the advice, emotional support, and most of all - for the food. I could not imagine a more amazing group of people to have met in my life, and l've learned so much from you all! 


\section{Table of Contents}

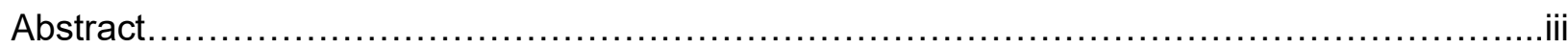

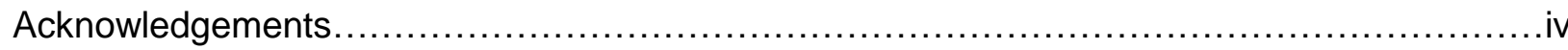

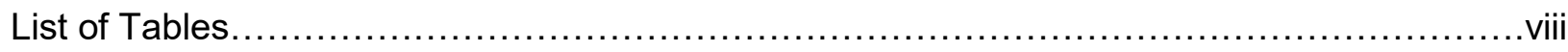

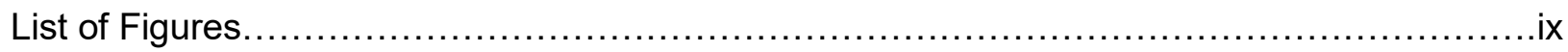

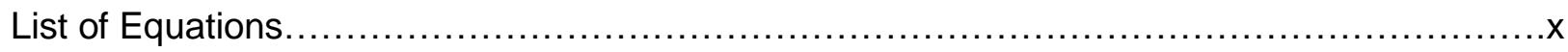

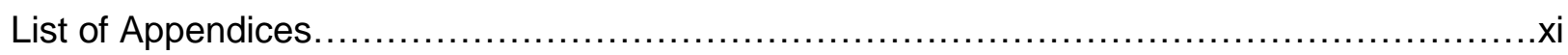

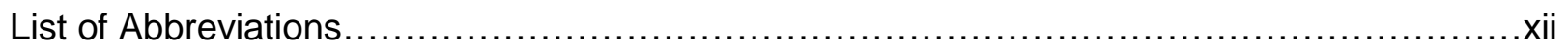

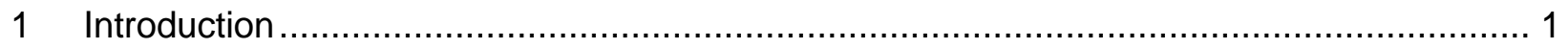

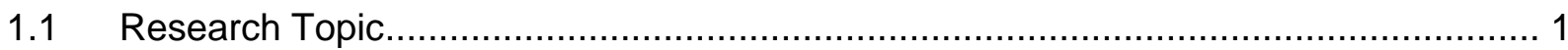

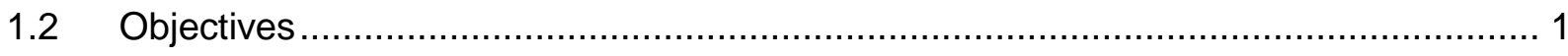

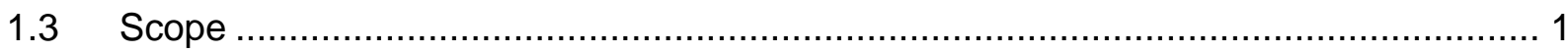

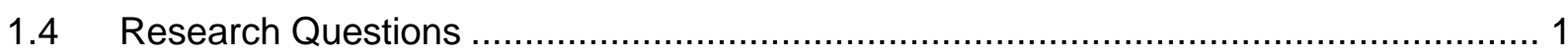

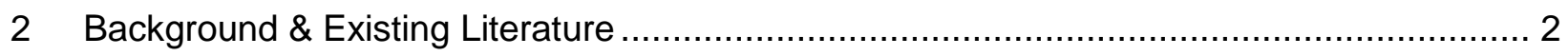

2.1 Challenges Associated with LEED .................................................................. 3

2.2 Assessing Building Performance Gaps ………................................................. 7

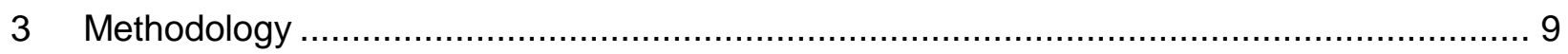

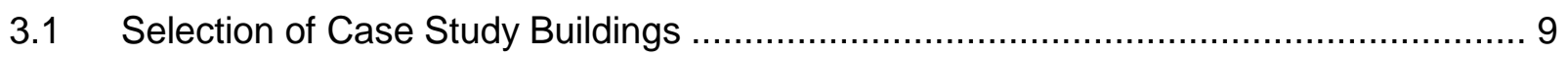

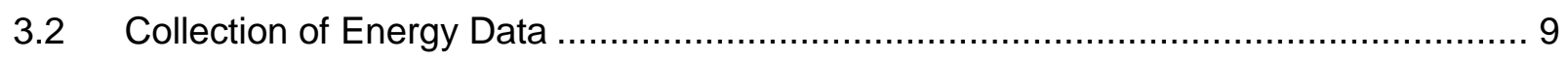

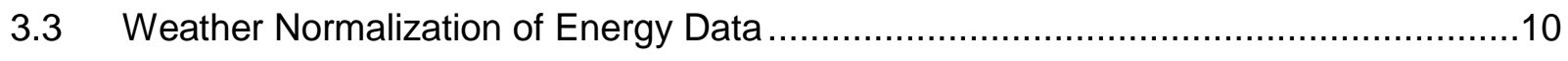


3.4 Rejection of Outliers and Missing Values ..................................................

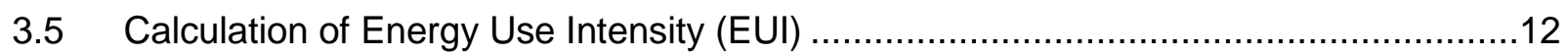

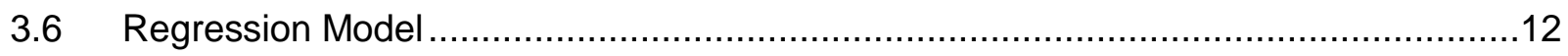

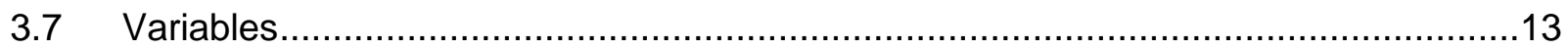

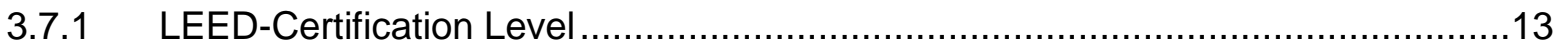

3.7.2 LEED Energy and Atmosphere Credits .............................................13

3.7.3 General Building Characteristics ............................................................

3.7.4 Energy Use (Heating, Cooling, Electricity) …........................................

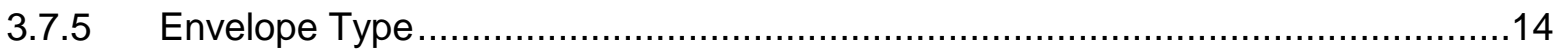

3.7.6 Surface Area to Volume Ratio............................................................ 15

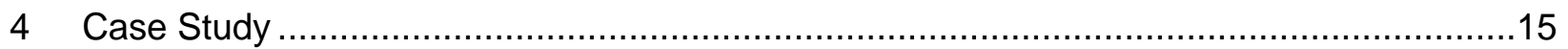

4.1.1 General Building Characteristics ............................................................... 15

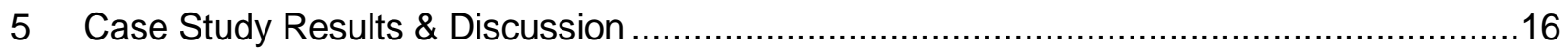

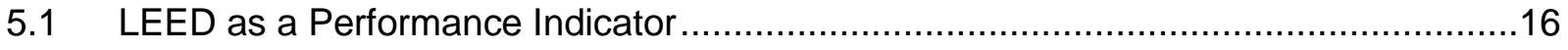

5.1.1 Predicted versus Actual Energy Use .................................................16

5.1.2 LEED Certification Level as a Predictor for Energy Use .................................18

5.1.3 LEED EAc1 Credits as a Predictor for Energy Use .....................................19

5.1.4 Performance Gap Between Average Similar Buildings.................................23

5.2 Effect of Building Characteristics on Energy Use ...............................................25

5.2.1 Building Height and Surface Area to Volume Ratio ........................................26

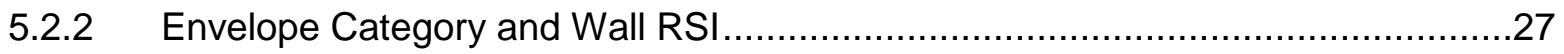




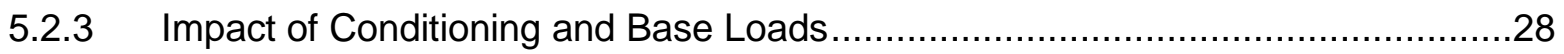

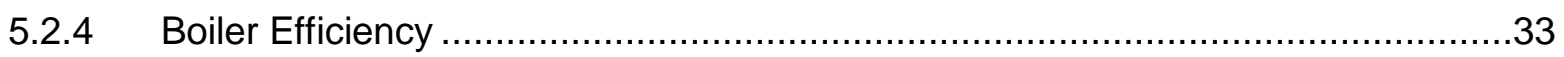

5.2.5 Chiller COP, Chiller Capacity and Cooling Tower Capacity ...............................33

5.2.6 Average Energy Use by Unit.......................................................................

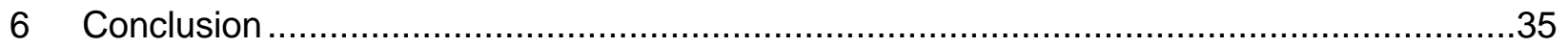

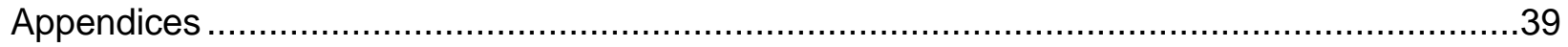

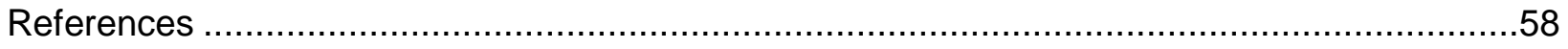




\section{List of Tables}

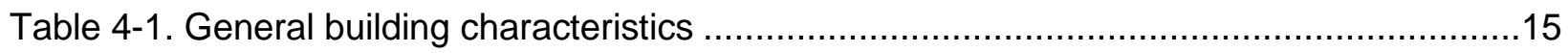

Table 5-1. MNCEB Improvement and Corresponding EAc1 Points (Canada Green Building

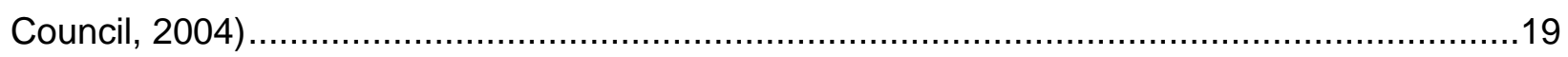

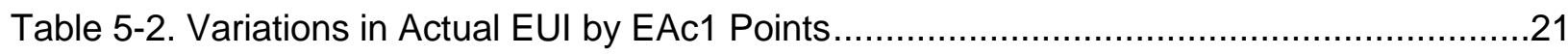

Table 5-3. Variation in Modelled EUI by EAc1 Points .........................................................21

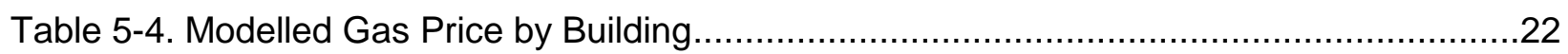

Table 5-5. Investigation into Cooling and Heating Load Inefficiency by Building........................30 


\section{List of Figures}

Figure 2-1. EUI and Realization Rate for Multifamily Residential Buildings (Cropp et al., 2014) . 4

Figure 5-1. Predicted versus Actual Energy Use

Figure 5-2. Relationship Between EAc1 Credits and EUI ...........................................20

Figure 5-3. Comparison to Average Building Stock ................................................24

Figure 5-4. Example of buildings with low surface volume to area ratios (left), and high surface

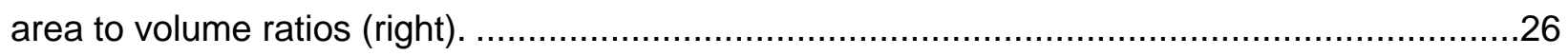

Figure 5-5. Surface Area to Volume Ratio's Effect on Heating EUI ......................................27

Figure 5-6. Heating as Percentage of Total EUI vs EUI.............................................29

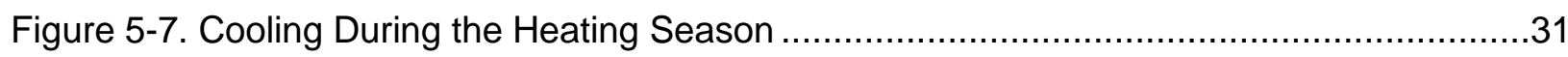

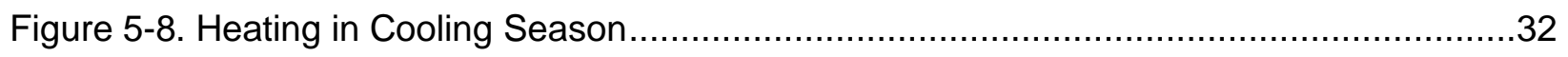

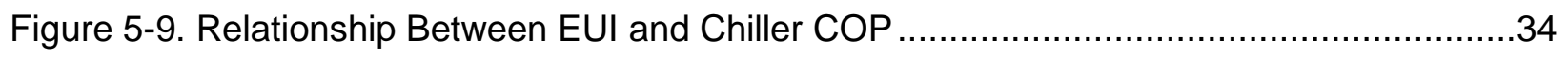

Figure 5-10. Standard Deviation of Suite Level Energy Use Over a 1 Year Period...................35 


\section{List of Equations}

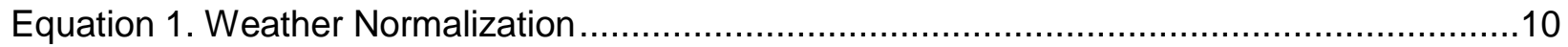

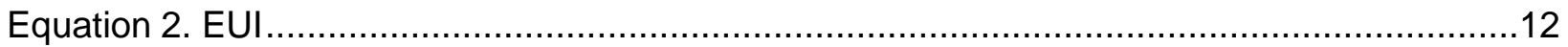




\section{List of Appendices}

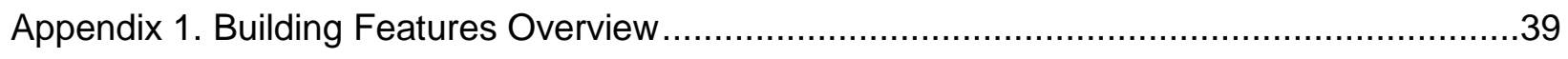

Appendix 2. Outputs of Regression Models ……............................................................. 


\author{
Abbreviated Terms \\ CaGBC - Canada Green Building Council \\ COP - Coefficient of Performance \\ EUI - Energy use intensity \\ GFA - Gross Floor Area \\ GHG - Green house gas \\ GTA - Greater Toronto Area \\ LEED - Leadership in Energy and Environmental Design \\ LEED NC - LEED for New Construction \\ MNECB - Model National Energy Code Building \\ MURB - Multi-unit residential building \\ USGBC - United States Green Building Council
}




\section{Introduction}

\subsection{Research Topic}

This study will examine energy use in LEED-certified mid-rise and high-rise multi-unit residential buildings (MURBs) in the Greater Toronto Area (GTA). As LEED-certified buildings built in Toronto from the mid-2000's and onwards are just now reaching a point where adequate real energy data is available to examine, this study focuses on making use of this newly collected data to better understand the relationship between LEED and building performance.

\subsection{Objectives}

The aim of this study is to assess the existence of a performance gap between the desired energy performance and the actual energy performance outcomes for LEED-certified multi-unit residential buildings within the GTA.

\subsection{Scope}

This study examines 19 multi-unit residential buildings, all located within the Greater Toronto Area. These case study buildings were selected for their completeness of information. Using metered data and utility information, modelling reports, and the LEED scorecards for each of the 19 buildings, a number of variables are examined. Trend analysis was then carried out to determine what the limiting factors are in LEED's ability to accurately predict and produce highperforming buildings.

\subsection{Research Questions}

The following research questions will be examined:

1. Given a sample set of case study buildings in the Greater Toronto Area, how accurately does design-stage energy modelling predict the actual energy use of a LEED-certified MURB? 
2. Within the LEED rating system, how much variation of energy performance can be seen between buildings which have reached the same level of certification? Given that there may be a difference in energy performance amongst buildings of the same level of certification, what is/are the key contributing factor(s) of this performance gap?

\section{Background \& Existing Literature}

LEED (Leadership in Energy and Environmental Design), is an international building rating system for "green buildings" (Canada Green Building Council, 2017). LEED Canada has existed since 2002, and represents a localized version of the LEED Certification system originally launched in the US (Canada Green Building Council, 2017). Currently, Canada has the second highest number of LEED Certified projects in the world, with 2,800 LEED buildings built since 2004 (Canada Green Building Council, 2017).

The LEED level achieved by a building is based on a checklist approach, where points are awarded for different achievements over six categories: Sustainable Sites, Water Efficiency, Energy and Atmosphere, Materials and Resources, Indoor Environmental Quality, and Innovation in Design. Increasing amounts of points are needed to reach each level of LEEDcertification, from Certified at the lowest level, to Silver, Gold, and Platinum at the highest.

Post-occupancy evaluations of building energy use and performance for green building rating programs such as LEED are integral to ensuring that the programming is working as intended to meet its goals. If the programming is not meeting these goals, the shortcomings must also be examined, and such analysis can be used to correct and improve future iterations of the rating system. Moreover, the examination of real energy data is important, as energy modelling simulations can only be so accurate, and cannot account for several factors including: changes 
made during the construction phase, unpredictable occupant behaviour, and other issues related to technological failures and unforeseen shortcomings. Using real data to inform our understanding of building performance as well as our ability to predict said performance helps eliminate some of the uncertainty surrounding the built environment and allows us to make better choices in the future.

\subsection{Challenges Associated with LEED}

A number of studies have already examined the LEED rating system, and have presented both the benefits and challenges associated with it. Turner \& Frankel (2008) published a study on the energy performance of LEED NC buildings in the United States, examining actual energy use compared to a number of metrics. The study found that building energy modelling done prior to the construction of these buildings had resulted in adequate predictions of average actual energy use outcomes (Turner \& Frankel, 2008). The median EUI of these LEED buildings was found to be $219 \mathrm{ekWh} / \mathrm{m}^{2}\left(69 \mathrm{kBTU} / \mathrm{ft}^{2}\right)$ (Turner \& Frankel, 2008). Moreover, LEED buildings were seen as delivering the desired savings, showing a $25-30 \%$ energy reduction on average over the national average of buildings found within the Commercial Buildings Energy Consumption Survey (CBECS) database (Turner \& Frankel, 2008).

Another study, produced by the Energy Trust of Oregon, found a "statistically significant positive correlation" between LEED Optimize Energy Performance (EAc1) points achieved and energy savings in their case study of LEED buildings (Cropp, Lee, Castor, \& Energy Trust of Oregon, 2014). The study included 10 LEED Gold and LEED Platinum multi-family residential buildings, which achieved between 1 to 10 EAc1 points out of a total of 10 achievable points (Cropp et al., 2014). The average EUI for these buildings is $114 \mathrm{ekWh} / \mathrm{m}^{2}\left(35.8 \mathrm{kBTU} / \mathrm{ft}^{2}\right)$, much lower than the averages for other types of buildings in the study including colleges/universities and office buildings (Cropp et al., 2014). 
The Energy Trust of Oregon study also examined the 'realization rate' of the projects - that is, the percentage of evaluated energy savings from as-built building energy simulation models versus reported energy savings from metered energy use (Cropp et al., 2014). Their research revealed an average realization rate of $92 \%$ for the multi-family residential category (Cropp et al., 2014). One predominant criticism of the majority of studies on LEED building performance is that the averages given actually represent a very wide range of energy uses, as seen in this study where realization rates range from $55 \%$ to $139 \%$ in the multi-family residential category alone (Cropp et al., 2014). This furthers the idea that averages presented within much of the literature can be misleading, and the actual result is a much more scattered, somewhat unpredictable picture of building performance.

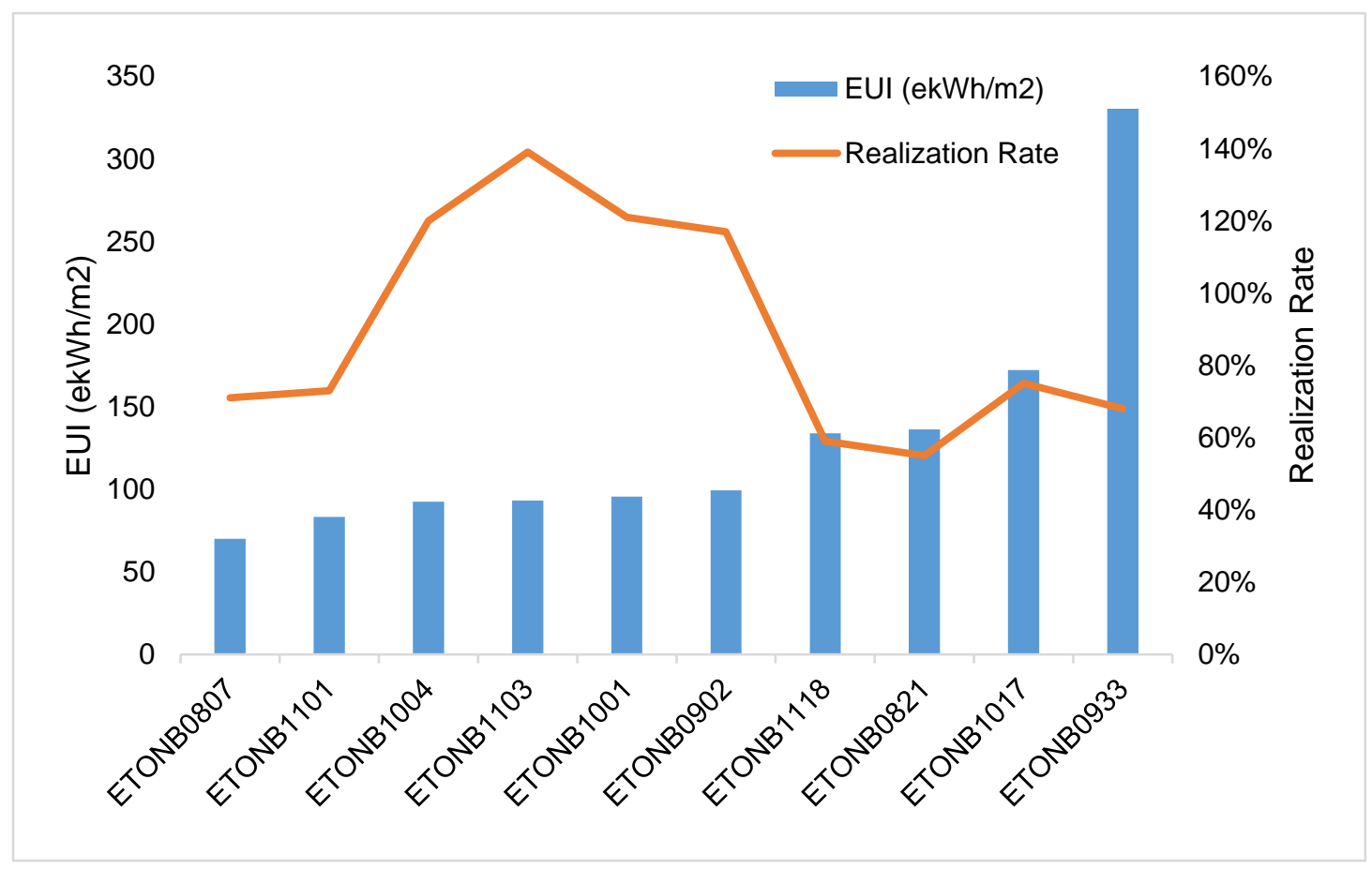

Figure 2-1. EUI and Realization Rate for Multifamily Residential Buildings (Cropp et al., 2014)

Chance (2012) examined 181 LEED-certified university buildings over several different years and different iterations of the US version of LEED. Using statistical analysis, they found that the 
Energy and Atmosphere Credit category is the "most powerful predictor of [LEED] rating", those buildings which gained more points in the EA category generally achieved a Gold or Platinum rating. They saw an average of $6.14 \mathrm{EA}$ credits out of 17 being achieved in this particular version of LEED. The study goes on to critique the LEED rating system, saying that the checklist-based method that the system employs "helps make invisible environmental factors visible, but some of its measures may be too simplistic to accurately predict performance" and that its "simplistic linear approaches are inadequate to address complex, ill-structured problems" (Chance, 2012). Lastly they noted that, within the buildings surveyed, there was an overall increase in EA credits from year to year, but they are unable to confirm whether this was due to a shift towards better building practices and performance, or simply the industry getting better at "chasing LEED points" (Chance, 2012).

Chokor (2015) examined the energy performance of LEED buildings in their case study, comparing five LEED-certified research facilities at Arizona State University in Texas against 13 similar non-LEED buildings in the same climate zone, climate zone 2B.

Chokor (2015) produces a performance model based upon the 13 non-LEED buildings, and then applies said model to the 5 LEED case study buildings. Heating, cooling, and electricity data as well as building characteristics are used to create a number of regression models to predict building energy use, including: multiple linear regression, gradient boosting regression, random forest regression, classification and regression tree, $\mathrm{k}$-nearest neighbors regression, kernel ridge regression, Bayesian ridge regression, and support vector regression (Chokor, 2015). The end goal was to examine how these regression models, which predicted building energy use based on EUI, would apply to the 5 LEED buildings, to examine if those buildings followed similar, predictable energy use patterns when compared to the non-LEED group. The gradient boosting regression model was eventually chosen as the most superior model in terms of accuracy towards the non-LEED buildings, as it produced the highest $R^{2}$ value. 
However, upon applying the gradient boosting regression model to the LEED buildings, the "non-homogenous performance" of said buildings was revealed (Chokor, 2015). No clear pattern was seen, as some buildings were underperforming while others were overperforming, and only one of the 5 buildings was within a reasonable range to the non-LEED buildings. Moreover, within this study there was no clear correlation between LEED EAc1 credits earned and actual building performance, as some buildings with less EAc1 credits were outperforming those with more credits (Chokor, 2015). A deeper investigation of the building's conditioning and electricity loads was then done to ascertain what differences may exist and overuse of the cooling system during shoulder seasons was revealed (Chokor, 2015). Ultimately the author felt that, "an assessment of LEED buildings' performance through comparing their actual energy consumption to that of the non-LEED benchmark shows the failure of LEED certification in saving energy", and that based upon the developed prediction model, there is an "inconsistency in the performance of LEED buildings" (Chokor, 2015).

Scofield (2013) published a much-cited case study on the efficacy of LEED-certification in reducing energy consumption and GHG emissions on office buildings in New York City. They critiqued existing studies surrounding LEED energy performance as being limited by the fact that most did not use randomly-selected building data, but rather 'self-selected' energy data from only the buildings who made this publicly available, (ie. better performing buildings) (Scofield, 2013). This, they argued, produced biased results. As most cities around the world historically have not implemented systems such as mandatory, publicly-available energy benchmarking for their buildings, it is clear that this bias can be at times unavoidable, as information on the existing building stock is not readily available. However, as New York has moved towards publicly disclosing building energy information for buildings of 50,000sf or larger, a suitable pool of data for a larger meta-analysis exists there (Scofield, 2013). Of 775 buildings that had information readily available, Scofield identified 257 as being LEED-certified, which 
was then reduced to a case study of 21 LEED buildings, based upon completeness within New York City's Energy Benchmarking data (Scofield, 2013).

Within this study it was found that LEED Gold buildings have $20 \%$ lower source energy, and $20 \%$ lower GHG emissions when compared to other New York City office buildings, but similar reductions are not seen in the lower tiers of the ranking system, LEED Silver and LEED Certified (Scofield, 2013). However, the 21 LEED buildings used slightly more energy than the 953 NYC buildings when comparing both site and source EUI, but not an amount which is statistically significant. However, the author states that their findings raise "serious questions regarding the scientific basis for government and institutional policies, such as New York City's local law 86 that require buildings to be LEED-certified in order to reduce GHG emissions", as the author does not think that the LEED rating system shows a significant correlation with energy performance.

\subsection{Assessing Building Performance Gaps}

When examining LEED's ability to produce high-performing, sustainable buildings, it is important to recognize that building energy modelling in itself is limited in its ability to accurately predict building energy use for a number of reasons. First, there is the idea that when technologies have been developed and tested for a considerable length of time, it becomes easier to predict their behaviour (Fedoruk, Cole, Robinson, \& Cayuela, 2015). Conversely, when a technology is new, there is little real-life application data available to input into a model, and therefore behavior is difficult to predict (Fedoruk et al., 2015). A model can only be as good as the quality and completeness of information that goes into it.

Fedoruk et al., (2015) argues that, as we moved towards more and more stringent sustainability considerations, we introduced more complexity into building energy modelling, increasing the uncertainty of the models. They go on to say that "[s]uch uncertainty is particularly the case when performance criteria are measured through predictive modelling techniques, with limited 
feedback of verified performance" (Fedoruk et al., 2015). This introduces an important concept - it is not enough to merely model a building, build it, and assume that everything is going as planned. Careful post-occupancy monitoring is necessary, and the data collected should be used to further calibrate the models going forward.

Similar views have been proposed by Menezes, Cripps, Bouchlaghem, \& Buswell, (2012), who examined predicted versus actual energy performance of non-domestic buildings. Using postoccupancy evaluation of an office building, they were able to determine ways in which different tenants operated different within similar spaces. What they found was the need to correct many assumptions that they had originally made in modelling, such as the assumption that all computers would be turned off after hours, when in actuality, building tenants were leaving them on to perform tasks throughout the night. The new, more informed model was able to accurately predict building energy use within $6 \%$ of actual consumption.

Another consideration, which is particularly challenging in residential buildings, is understanding the impacts of occupant behaviour on energy use. Modelling becomes more and more difficult as the number of unpredictable variables increases. Unlike in an office, school, or other predictable space, occupancy schedules for residential buildings are not tied to a set behavioral pattern such as 9 to 5 work hours. As well, in the case of buildings with individually submetered suites and separate thermostats, further complexity is introduced by the fact that occupants may choose different setpoints based on their preferences. A recent study of highrise MURBs within Toronto showed that even in high-performing buildings, the EUI of suites can vary by as much as a factor of 7, due to occupant behaviour (Brown, Gorgolewski, \& Goodwill, 2015).

Furthermore, as these occupants may not fully understand the sustainability features of a building, they may be prone to making changes to their suites that negatively impact building performance. A study of occupant satisfaction and comfort within LEED Gold MURBs in Toronto 
showed that $52.9 \%$ of occupants surveyed did not use their ERV in the winter, because they did not know how, they did not like the noise it created, or they did not like the hassle of cleaning it (Brown \& Gorgolewski, 2014). This is something that would not be easily predictable by an energy model alone. Residential occupancy adds to the uncertainty and confusion surrounding the prediction of building energy performance. Certainly, building energy modelling is a powerful tool, however the accuracy of this tool can be compromised by the above factors, and therefore buildings can be seen as 'underperforming' as a result.

\section{Methodology}

\subsection{Selection of Case Study Buildings}

Case study sample buildings were selected out of a larger pool of 24 high-rise MURBs located within the GTA. The 19 buildings were selected out of this pool as they had the necessary information available, including metered building energy use as well as having made publicly available the LEED Scorecards for the project, from which the LEED EAc1 credit points could be determined. Out of the selected buildings, it was not possible to obtain in some cases, adequate information on the design-stage modelling of the buildings, however as actual energy use information was included, these buildings were not selected against. This is to ensure that the sample size for the study was large enough to make comparisons.

\subsection{Collection of Energy Data}

Three years of metered energy data was collected from the buildings' installed metering systems, including sub-metered data for individual suites. Monthly energy reports were used, which provided the meter reading at the beginning and end of each month. This information was divided into: heating, cooling, electricity, and gas by the metering platform. In most cases the gas load only represented the gas used for heating domestic hot water, but in cases where it 
did not, this had to be separated manually so that the gas used for the heating systems was removed from the baseload calculation and appropriately weather normalized (see Section 3.3).

The buildings selected for this research were chosen for their completeness of information, both in terms of information surrounding LEED-certification (such as LEED Scorecards) as well as information about the building itself. However, quality of information varies by building. The collected data covered the period from August 2014 to July 2017 for the majority of the buildings. In the cases of buildings $014 \mathrm{~A}, 014 \mathrm{~B}, 016$, and 017 , energy information was only available for a two-year period from August 2015 to July 2017.

\subsection{Weather Normalization of Energy Data}

After collection, the three years of energy data for each building was weather normalized. Weather normalization was done using a simple ratio calculation method outlined by Brown, Turcato, \& Gorgolewski, (2015). This method involves the Heating Degree Days (HDD) and Cooling Degree Days (CDD), and kWh of conditioning energy use - heating and cooling respectively. The threshold points for $\mathrm{HDD}$ were below $18.3^{\circ} \mathrm{C}$ and for CDD, above $18.3^{\circ} \mathrm{C}$.

A historical average of HDDs and CDDs over a 30-year period was used as the reference for which to normalize the data (Brown, Turcato, et al., 2015). This historical average was retrieved from the Government of Canada's Climate Normals from the Toronto weather station, for the period from 1981 to 2010 (Government of Canada, n.d.).

The calculation is as follows, (Brown, Turcato, et al., 2015):

\section{Equation 1. Weather Normalization}

$$
\text { heating }(k W h)=\frac{H D D \text { of year }}{H D D \text { of } 30 \text { year avg }}
$$


This normalization was done to account for any abnormal weather events occurring in the threeyear period that was examined, which may have otherwise caused unnatural spikes in energy use.

\subsection{Rejection of Outliers and Missing Values}

Outliers within the raw data had to be cleansed and removed. The population standard deviation and mean value for each set of data, month by month, were calculated. Using Excel's standardize function, outliers were calculated; the threshold for determining values was +-2.5 .

In some cases, there were large amounts of missing values or errors within the monthly energy reports, making the data for that specific month highly unreliable. The following procedure was adopted from a guide to building benchmarking by Brown, Turcato, et al., (2015). If any given month was missing significant portions of data, and data for the same month of the previous and next year was available, those two values were averaged to create the value for the missing month (ie. December of 2015 and December of 2017 could be averaged to produce values for December 2016). If for some reason this was not possible (for example the buildings with only two years of energy data available) the previous and proceeding month were averaged instead (ie. November 2016 and January 2017 could be averaged to produce values for December 2016). As was advised, when three consecutive months or more of building energy data was unavailable, the data for that year was simply not used (Brown, Turcato, et al., 2015). However, there were almost no instances in which data was missing for a long enough time span to cause an issue. The resulting weather-normalized totals were used to produce the yearly EUI for each building, which forms the main basis of comparison for this study. 


\subsection{Calculation of Energy Use Intensity (EUI)}

The energy use intensity or EUI - measured in equivalent kilowatt hours per $\mathrm{m}^{2}\left(\mathrm{ekWh} / \mathrm{m}^{2}\right)$ was calculated for each building based on an average of the weather normalized 3-year energy use data.

The calculation for EUI is:

\section{Equation 2. EUI}

$$
E U I=\frac{\text { avg.yearly total energy use }(e k W h)}{G F A\left(m^{2}\right)}
$$

EUI was chosen as the metric for comparison for this study as it represents real energy use, rather than improvement over a hypothetical number (such as a certain percentage over MNECB code) (Brown, Turcato, et al., 2015). EUI normalizes energy use over the buildings floor area, and is a commonly used metric in energy benchmarking programs as it allows for the comparison of multiple buildings of different sizes more reasonably

\subsection{Regression Model}

Statistical analysis was carried out using the above described variables to determine which variables had the largest impact on key building performance aspects. Simple linear regressions and multi-variate linear regressions were undertaken using the Regression function in Excel's Analysis ToolPak add-in. After running simple linear regressions on all variables to assess their statistical significance ( $p$ value) and R2 values, specific combinations of promising variables were combined to undergo multi-variate linear regressions. The outputs of the regression model can be found in Appendix 2. 


\subsection{Variables}

\subsubsection{LEED-Certification Level}

The LEED-certification level achieved by each building will be examined. The LEED version LEED New Construction 1.0 - which this case study's buildings fall under - has a range of certification levels from Certified (the lowest level) to Gold (the highest level). This study will focus on Gold and Silver level buildings.

\subsubsection{LEED Energy and Atmosphere Credits}

One key indicator that will be examined is LEED Energy and Atmosphere Credits - specifically, the Energy and Atmosphere Credit 1 (EAc1) credit, which applies to both the prescriptive and performance based certification paths. The points that can be achieved for this credit range from one to ten, and the credit is intended to push LEED users to strive for additional energy efficiency above the LEED Prerequisite. These points are awarded based on the building's ability to meet a certain percentage of design energy cost reductions over the energy cost of an equivalent reference building. Using energy modelling, the design case and a reference case, which follows either MNECB/CBIP or ASHREA/IESNA 90.1-1999, are simulated and compared. This data was gathered from CaGBC's LEED Project database, as well as from the energy modelling reports provided.

It is important to note that EAc1 credits are awarded based upon an energy cost comparison, not energy use intensity or even total kilowatt hours of energy used. Moreover, LEED only accounts for the building's site energy, not source energy, and it also does not take into account any energy generated on-site by renewable energy sources. The energy cost reduction also does not include any miscellaneous, non-regulated loads. These parameters all have important consequences for our understanding of the meaning of "energy" in the LEED context. 


\subsubsection{General Building Characteristics}

General building characteristics included the gross floor area (GFA) of the buildings, the number of units, and the number of floors. This information was gathered from modelling reports provided, and when not provided, information such as number of units, building height, and building footprint size was gathered from condominium websites, the City of Toronto's 3D Massing Tiles, and Google Maps.

\subsubsection{Energy Use (Heating, Cooling, Electricity)}

Metered energy use data from each of the buildings was collected. This data is categorized into two categories:

1. Conditioning load, which includes heating energy and cooling energy and;

2. Base load which includes other loads such as lighting, domestic hot water heating, and other miscellaneous energy loads such as use of electricity for appliances.

This is based on the categories of energy use presented in the raw data - marked as "cooling", "heating", "electricity" and "gas", with some exceptions - energy uses originally marked as "gas" were further divided into heating and base load, depending on if the gas use was related to the conditioning boiler or the domestic hot water boiler, to the author's best ability. It should be noted that information on additional conditioning devices that occupants may have, including air conditioners, fans, or portable heaters is not captured within the categories of heating or cooling loads in the raw data provided, and would instead be captured within the category base loads as is typical with most studies on MURBs.

\subsubsection{Envelope Type}

This was gathered from the modelling reports provided, as well as some additional architectural drawings. Buildings were categorized based on those which had similar construction and envelope characteristics. 
The envelope categories developed are:

1. Spandrel (Average RSI 2.56)

2. Concrete/Stucco (Average RSI 2.48)

3. Brick Façade (Average RSI 2.80)

Envelope properties such as R-value and composition vary slightly between envelope types, however they are generally similar enough to create a comparison.

\subsubsection{Surface Area to Volume Ratio}

The surface area to volume ratio was calculated using the City of Toronto's 3D Massing files for SketchUp, which provided the approximate geometry of the case study buildings ${ }^{1}$. Using the modelling software, the surface area and volume of each building could be accurately calculated.

\section{Case Study}

This research centres around a case study of 19 mid-rise to high-rise condominium buildings located in the GTA. All of the buildings within the study are condominiums and therefore have individual sub-metering of the units, as well as individual metering for most of the components of the HVAC equipment, boiler plant, and the like. More information on the general building characteristics can be found in Table 4-1.

\subsubsection{General Building Characteristics}

Table 4-1. General building characteristics

\begin{tabular}{|l|c|r|c|c|}
\hline Building & LEED Certification & \multicolumn{1}{|c|}{ Floors } & GFA (m2) & EUI $\left(\mathbf{k W h} / \mathbf{m}^{2}\right)$ \\
\hline $\mathbf{0 0 1}$ & Silver & 8 & 17,572 & 224 \\
\hline $\mathbf{0 0 2}$ & Gold & 40 & 37,387 & 365 \\
\hline
\end{tabular}

${ }^{1}$ Building 001 was not included in the massing tiles and therefore was not included in this comparison. 


\begin{tabular}{|c|c|c|c|c|}
\hline 003 & Gold & 34 & 32,017 & 236 \\
\hline 004 & Silver & 30 & 35,651 & 346 \\
\hline 005 & Silver & 29 & 30,475 & 181 \\
\hline 006-A & Gold & 25 & 21,614 & 245 \\
\hline 006-B & Gold & 27 & 31,912 & 239 \\
\hline 007 & Silver & 33 & 22,222 & 222 \\
\hline 008-A & Gold & 34 & 29,902 & 490 \\
\hline 008-B & Gold & 35 & 30,556 & 616 \\
\hline 009 & Gold & 49 & 56,483 & 465 \\
\hline 010 & Gold & 36 & 29,506 & 263 \\
\hline 011 & Gold & 9 & 19,908 & 219 \\
\hline 014-A & Gold & 27 & 19,713 & 546 \\
\hline 014-B & Gold & 30 & 21,859 & 466 \\
\hline 015-A & Gold & 12 & 28,913 & 415 \\
\hline 015-B & Gold & 10 & 20,481 & 354 \\
\hline 016 & Gold & 21 & 22,162 & 107 \\
\hline 017 & Silver & 21,15 & 46,854 & 396 \\
\hline
\end{tabular}

The case study buildings range from 8 to 49 storeys in height, with the average height being 27 storeys, and range in GFA from $17,572 \mathrm{~m}^{2}$ to $56,483 \mathrm{~m}^{2}$, with the average GFA being $29,220 \mathrm{~m}^{2}$.

\section{Case Study Results \& Discussion}

\subsection{LEED as a Performance Indicator}

\subsubsection{Predicted versus Actual Energy Use}

As part of the LEED EAc1 credit process, energy modelling was done by the project team to produce two figures for comparison. The first is the design model, which is used to calculate the approximate predicted energy use of the future project. This is compared to a second model, the MNECB model, which is a building of similar design and characteristics of the design model, however it reflects design strategies only up to MNECB code and therefore does not include any of the "green building" technologies or energy saving measures that the design model employs. 
The MNECB model is used to suggest the 'bare minimum' or typical to current industry case, upon which the LEED design must reach a certain percentage of improvement to obtain EAc1 points. The outputs of these models make up the majority of comparisons within this study.

Both the MNECB reference model and the design model exclude what LEED defines as "nonregulated loads" - this includes exterior lighting, garage ventilation, elevators, process loads and most important plug loads - which, as described in Section 2.2, are one of the largest sources of energy use variation in MURBs (Canada Green Building Council, 2004). However, these loads are of course present in the actual EUI of the building as they represent a very important facet of building energy use - occupancy.

When we compare the case study buildings to their modelled counterparts, we find quite the discrepancy in numbers. The figure below compares the actual energy use (metered), predicted energy used (modelled), and the MNECB reference case energy use (modelled) presented as EUI.

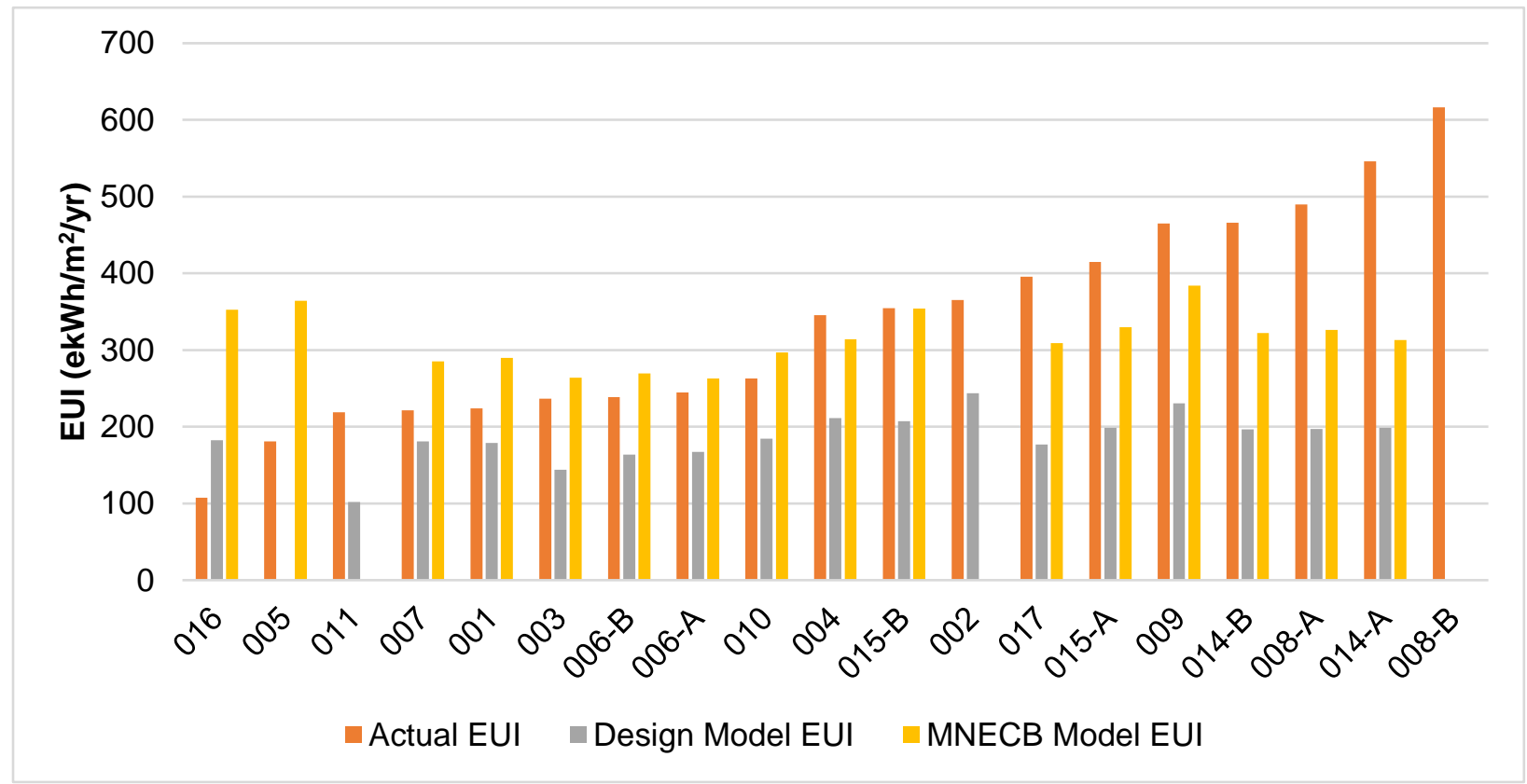

Figure 5-1. Predicted versus Actual Energy Use 
The average actual EUI for our case study buildings is $337 \mathrm{ekWh} / \mathrm{m}^{2}$, compared to $188 \mathrm{ekWh} / \mathrm{m}^{2}$ for their design model counterparts, and $315 \mathrm{ekWh} / \mathrm{m}^{2}$ for the MNECB base models. In fact, the case study buildings are closer in EUI to the MNECB "business as usual" scenario than they are to their predicted outcomes. On average, the case study buildings had a $76 \%$ higher EUI than their design model predicted, but this ranged from a $41 \%$ improvement to as much as a $175 \%$ increase in energy use. This trend is similar to what has been seen in the studies by Chokor, (2015) and Cropp et al., (2014), leading them to criticize LEED as being highly unreliable.

There are a number of other limitations to building energy modelling as well. For example, within many of the modelling reports for the case study buildings, energy modellers have cited limitations in accurately representing the large-scale commercial HVAC system components such as boilers, chillers, or cooling towers. In many cases newer technology, such as VFD or modulating technology is difficult to model; some equipment was modelled as several smaller pieces of similar equipment instead. In some cases, several plants were modelled as one plant, or vice versa, especially in the case of those buildings which are actually two buildings with integrated systems.

\subsubsection{LEED Certification Level as a Predictor for Energy Use}

Within this case study there are 14 LEED Gold buildings and 5 LEED Silver buildings; the average EUI for LEED Gold buildings is $360 \mathrm{ekWh} / \mathrm{m}^{2}$, and for LEED Silver it is lower, at 274 $\mathrm{ekWh} / \mathrm{m}^{2}$. One of the main criticisms of LEED is that, since it is a checklist based rating system it's easy to stack points in a certain area or to pick and choose credits which are easier to achieve, but with less direct impact on reducing the actual environmental burden of the building. In this case, within the LEED Gold level, we see a difference between building EUIs of 509 $\mathrm{ekWh} / \mathrm{m}^{2}$, with the highest consuming building having an EUI five times more than the lowest building within the same level of certification. The difference within the LEED Silver buildings is 
less extreme, at $215 \mathrm{ekWh} / \mathrm{m}^{2}$, but still significant. This betrays some of the limitations of the LEED system and its ability to lead the industry towards a more sustainable building stock.

It is interesting to note that, between the 19 buildings, when comparing the EUI of the design models, there is a difference of only $42 \%$, compared to a difference of nearly $500 \%$ for the actual energy use of the buildings. The LEED Gold building design models had an average EUI of $186 \mathrm{ekWh} / \mathrm{m}^{2}$, and the LEED Silver design models had an average EUI of $187 \mathrm{ekWh} / \mathrm{m}^{2}$. Even within the design models, LEED level does not appear to be a major deciding factor in the EUI of buildings.

\subsubsection{LEED EAc1 Credits as a Predictor for Energy Use}

The LEED EAc1 Credit category has been mentioned in some studies as the most accurate predictor of energy use within the LEED Certification system. EAc1 credits are awarded based upon a percentage reduction against either an MNECB or ASHRAE/IESNA 90.1-1999 reference building (Canada Green Building Council, 2004). The points to be achieved through both options are reflected in Table 5-1 below.

Table 5-1. MNCEB Improvement and Corresponding EAc1 Points (Canada Green Building Council, 2004)

\begin{tabular}{|c|c|c|}
\hline EAc1 Points & Reduction over MNECB & $\begin{array}{l}\text { ASHRAE/IESNA 90.1- } \\
\text { 1999 }\end{array}$ \\
\hline 1 & $24 \%$ & $15 \%$ \\
\hline 2 & $29 \%$ & $20 \%$ \\
\hline 3 & $33 \%$ & $25 \%$ \\
\hline 4 & $38 \%$ & $30 \%$ \\
\hline 5 & $42 \%$ & $35 \%$ \\
\hline 6 & $47 \%$ & $40 \%$ \\
\hline 7 & $51 \%$ & $45 \%$ \\
\hline 8 & $55 \%$ & $50 \%$ \\
\hline
\end{tabular}




\begin{tabular}{|c|c|c|}
\hline 9 & $60 \%$ & $55 \%$ \\
\hline 10 & $64 \%$ & $60 \%$ \\
\hline
\end{tabular}

The buildings within the case study received between 2 to 9 credits in the EAc1 category. Although all the buildings scoring above 5 EAc1 points are LEED Gold, both LEED Gold and LEED Silver buildings scored 3-5 points, and one LEED Silver building scored 2 points. However, when examining the EUI of these buildings against the amount of EAc1 points achieved, the expected trend towards decreasing energy use with increasing EAc1 points is not evident. Some of the least energy intensive buildings scored a mere 2 EAc1 points, while some buildings with 9 EAc1 credits find themselves on the higher end of that spectrum.

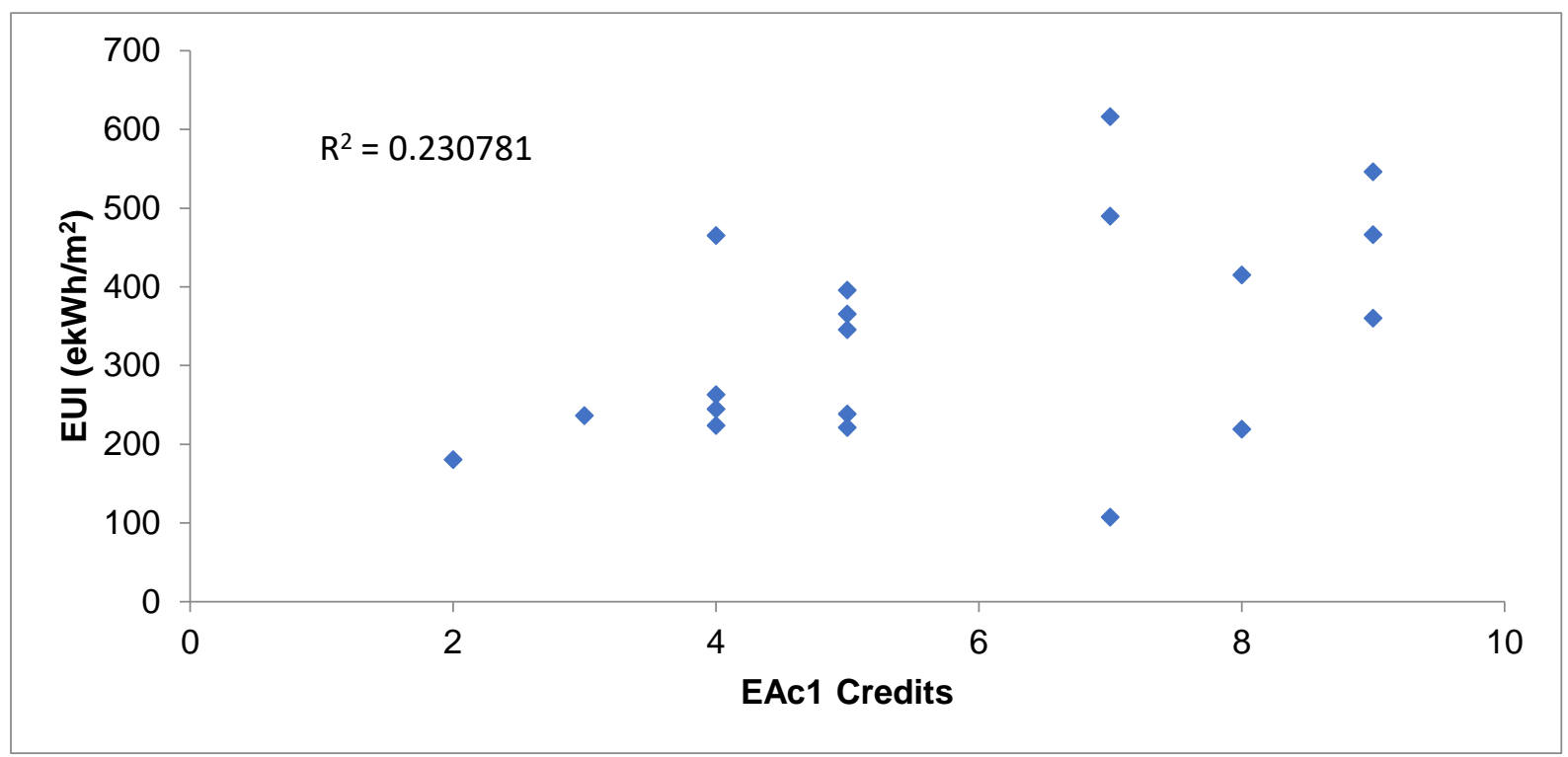

Figure 5-2. Relationship Between EAc1 Credits and EUI

The above simple linear regression represents the relationship between LEED EAc1 credits and building EUI. The regression model returned an $R^{2}$ value of 0.230781 , and a $p$ value of 0.037 indicating that this relationship. Despite the low $\mathrm{R}^{2}$, the $\mathrm{p}$ value suggests that this relationship has a moderate degree of statistical significance. The resulting coefficient is 30.71 , indicating that a change of $1 \mathrm{EAc} 1$ credit results in an EUI increase of $30.71 \mathrm{ekWh} / \mathrm{m}^{2}$. This result is surprising as EAc1 credits were anticipated to be the strongest indicator of energy performance, 
based on the previous research and works mentioned in Section 2. However, it appears that within this case study, no such correlation occurs.

In terms of variation between building EUls for a certain number of credits awarded, the following table represents the averages for each point gained under the EAc1 credit category. Values for points where one or less data point exist have been omitted.

Table 5-2. Variations in Actual EUI by EAc1 Points ${ }^{2}$

\begin{tabular}{|l|l|l|l|l|l|}
\hline \multicolumn{1}{|c|}{ EAc1 } & Average EUI & \multicolumn{1}{c|}{ Min. EUI } & \multicolumn{1}{c|}{ Max. EUI } & Difference & Difference \\
\hline 4 & 299 & 224 & 465 & 241 & $208 \%$ \\
\hline 5 & 313 & 222 & 396 & 174 & $179 \%$ \\
\hline 7 & 405 & 107 & 616 & 509 & $574 \%$ \\
\hline 8 & 317 & 219 & 416 & 196 & $53 \%$ \\
\hline 9 & 458 & 360 & 546 & 186 & $152 \%$ \\
\hline
\end{tabular}

Examining the design models based upon EAc1 points targeted reveals similar results. On average 4 EAc1 points resulted in a modelled EUI of $190 \mathrm{ekWh} / \mathrm{m}^{2}, 5$ points resulted in an EUI of $195 \mathrm{ekWh} / \mathrm{m}^{2}$, and 7 points resulted in $190 \mathrm{ekWh} / \mathrm{m}^{2}$. Those buildings aiming for 9 out of 10 possible EAc1 points actually had models with the highest EUls, an average of $201 \mathrm{ekWh} / \mathrm{m}^{2}$.

Table 5-3. Variation in Modelled EUI by EAc1 Points ${ }^{3}$

\begin{tabular}{|l|l|l|l|l|l|}
\hline \multicolumn{1}{|c|}{ EAc1 } & Average EUI & \multicolumn{1}{c|}{ Min. EUI } & Max. EUI & Difference & Difference \\
\hline 4 & 190 & 167 & 231 & 63 & $138 \%$ \\
\hline 5 & 195 & 164 & 244 & 80 & $149 \%$ \\
\hline 7 & 190 & 182 & 197 & 15 & $108 \%$ \\
\hline 8 & 150 & 102 & 198 & 96 & $52 \%$ \\
\hline 9 & 201 & 196 & 207 & 11 & $105 \%$ \\
\hline
\end{tabular}

2 There are only two buildings which scored 8 points.

3 There are only two buildings which scored 8 points. 
This reveals that neither LEED Level nor LEED EAc1 points had a strong correlation with decreased energy use for the sample studied, both in simulation and actual outcomes.

It is important to bear in mind that the LEED EAc1 credit is based upon savings of energy cost, rather than savings of energy used, therefore the targets to be reached for the EAc1 credit are certain percentages of cost reduction over the MNECB model (Canada Green Building Council, 2004). Because of this, it is possible that buildings which underwent energy modelling for their LEED EAc1 credits at different time periods may be able to receive the same level of cost reduction, while actually using more energy simply because utility costs were lower that year.

A closer look was take at the energy costs for different buildings within the study, as represented in the energy modelling reports. Electricity costs did not vary significantly, at around $\$ 0.08 / \mathrm{kWh}$. Gas prices did vary, between $\$ 0.32 / \mathrm{m}^{3}$ to $\$ 0.49 / \mathrm{m}^{3}$, this can be seen in Table 5-4.

Table 5-4. Modelled Gas Price by Building ${ }^{4}$

\begin{tabular}{|l|l|l|l|}
\hline Building No. & EAc1 Credits & Gas Price $\mathbf{( \$ \mathbf { m } 3 )}$ & Year Modelled \\
\hline 001 & 4 & 0.49 & 2008 \\
\hline 004 & 5 & 0.41 & 2009 \\
\hline 005 & 2 & 0.49 & 2005 \\
\hline $006-A$ & 4 & 0.41 & 2009 \\
\hline $006-B$ & 5 & 0.42 & 2011 \\
\hline 007 & 5 & 0.42 & 2011 \\
\hline $008-A$ & 7 & 0.32 & 2015 \\
\hline $008-B$ & 7 & 0.32 & 2015 \\
\hline 009 & 4 & 0.41 & 2009 \\
\hline 010 & 4 & 0.42 & 2011 \\
\hline $014-A$ & 9 & 0.42 & 2014 \\
\hline $014-B$ & 9 & 0.42 & 2014 \\
\hline
\end{tabular}

${ }^{4}$ Buildings 002, 003, 011 are not listed as utility pricing information was not available. 


\begin{tabular}{|l|l|l|l|}
\hline $015-A$ & 8 & 0.42 & 2015 \\
\hline $015-B$ & 9 & 0.42 & 2015 \\
\hline 016 & 7 & 0.42 & 2011 \\
\hline 017 & 5 & 0.42 & 2011 \\
\hline
\end{tabular}

Despite the variation, the majority of the buildings modelled over the period between 2008 to 2015 are consistently at $\$ 0.42$, making it difficult to examine if utility pricing truly has a hand in making it easier to achieve LEED EAc1 points.

\subsubsection{Performance Gap Between Average Similar Buildings}

While assessing LEED's ability to accurately predict energy performance through modelling is important, another pertinent angle to examine is how LEED buildings in Toronto stack up against the existing building stock. If the CaGBC's mandate is "Every Building Greener", then certainly Toronto's LEED buildings must show an improvement over existing ones, even if that difference is smaller than has been predicted by the design models (Canada Green Building Council, 2017).

Two existing sources which examine the historical energy use of MURBs in Canada are the National Energy Use Database (NEUD) and the Survey of Household Energy Use (SHEU). These sources provide average energy uses for specific types of buildings by province. However, as noted by Huang (2012), the numbers provided do not reflect other, smaller case studies on the existing building stock, and provide a difficult comparison to sample sizes of existing buildings as the information itself was sourced from energy use reported on a household energy survey, not measured data.

A study published by The Atmospheric Fund (TAF) in 2012 examined the energy use intensities of Toronto MURBs built from 1960 to 2010 (Binkley, Touchie, \& Pressnail, 2012). This study found an average energy intensity of $292 \mathrm{ekWh} / \mathrm{m}^{2}$ from a dataset of 40 buildings, a number which the authors found consistent with EUI values they examined in a larger meta-analysis 
(Binkley et al., 2012). Huang (2012), similarly examined sample study of 42 buildings, some of which overlap with the buildings examined in the TAF study. They found an average normalized annual energy consumption of $336 \mathrm{ekWh} / \mathrm{m}^{2}$. This is almost exactly the average EUI of the case study sample, at $337 \mathrm{ekWh} / \mathrm{m}^{2}$, indicating that in general the LEED MURBs represented in this case study are not performing any better than the average building stock, despite being of newer, and "greener" construction. Both values have been shown against the actual and design EUI of the case study buildings, as seen in Figure 5-3.

Taking a closer look at the individual buildings, when the case study sample was compared to the TAF benchmark, half of the sample is performing better than the average high-rise MURB within the GTA. 9 out of the 19 buildings performed better than an average MURB, while the remaining 10 underperformed by varying degrees. A similar trend is represented when comparing Huang's case study as well.

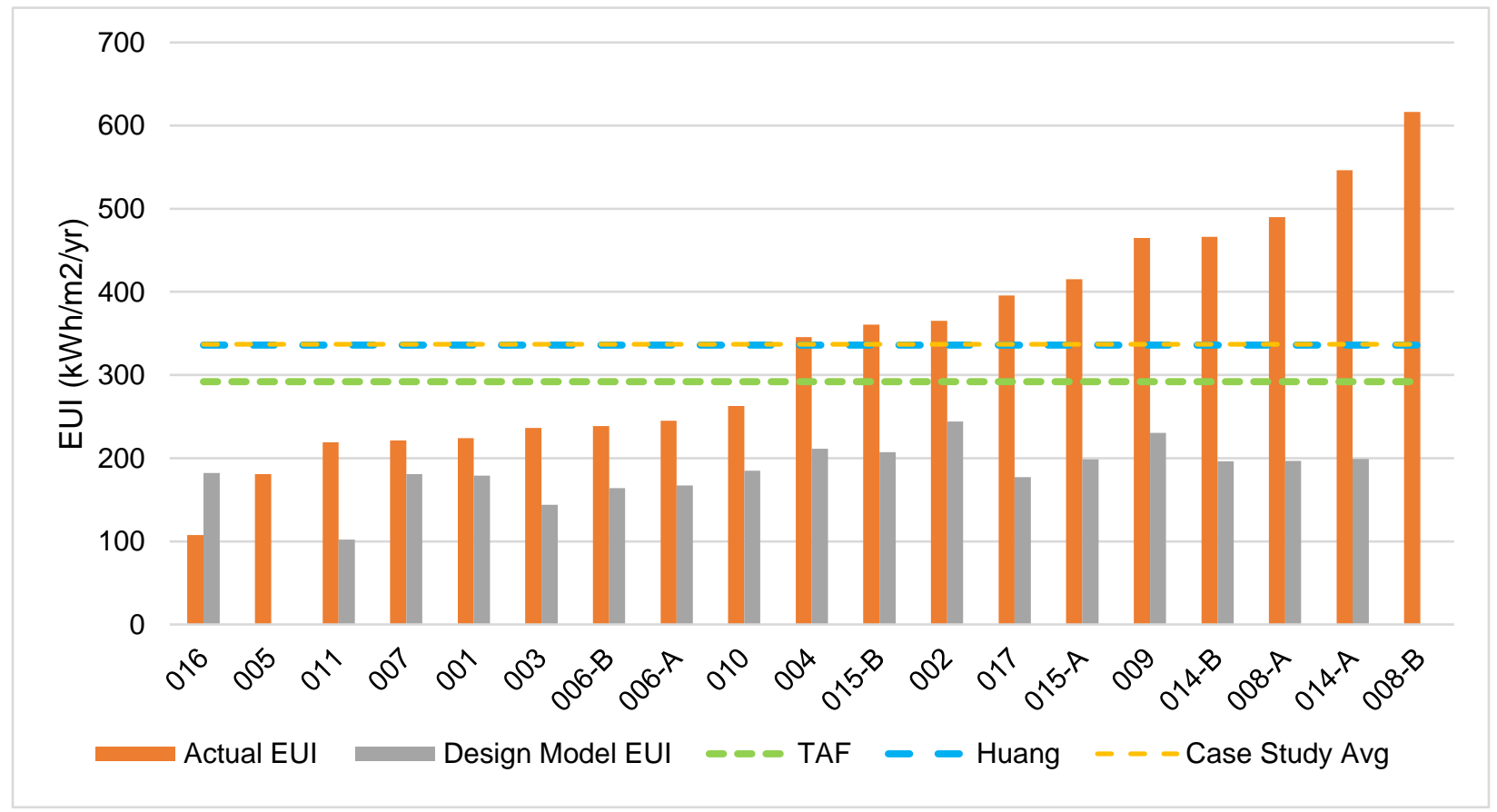

Figure 5-3. Comparison to Average Building Stock 
Of the 9 buildings that performed better than the benchmarks, an average of $26 \%$ improvement was seen, from a range of $10 \%$ to as much as $63 \%$ energy reductions. In nominal terms, they are saving between $29 \mathrm{ekWh} / \mathrm{m}^{2}$ and $185 \mathrm{ekWh} / \mathrm{m}^{2}$, for an average of $69 \mathrm{ekWh} / \mathrm{m}^{2}$ per year over the average Toronto MURB - by no means an insignificant amount of reductions.

The remaining ten buildings performed an average 50\% worse than the TAF benchmark, from a range of $18 \%$ to $111 \%$ increased energy use. Examining the case study sample against the above benchmarks reinforces the idea that there is a consistent struggle of LEED to accurately demonstrate energy use reductions, sometimes having great successes, and at other times grave failures.

\subsection{Effect of Building Characteristics on Energy Use}

It is pertinent to look past the LEED rating system itself, and instead consider what factors may be causing this performance gap in some of Toronto's supposedly highest performing, environmentally friendly MURBs. The following section will examine building characteristics that may have played a part in reducing the performance of these buildings. 


\subsubsection{Building Height and Surface Area to Volume Ratio}

One factor influencing the energy use of a building is the surface area to volume ratio, as a large surface area to volume ratio would create greater opportunity for heat to be lost through the envelope (Straube \& Burnett, 2005). Figure 5-4 represents examples of case study buildings with low surface area to volume ratios and high surface area to volume ratios, respectively. The buildings with a low surface area to volume ratio are, in general, shorter buildings with a more horizontal profile; those with a higher surface area to volume ratio have a vertical profile and often represent the taller buildings.
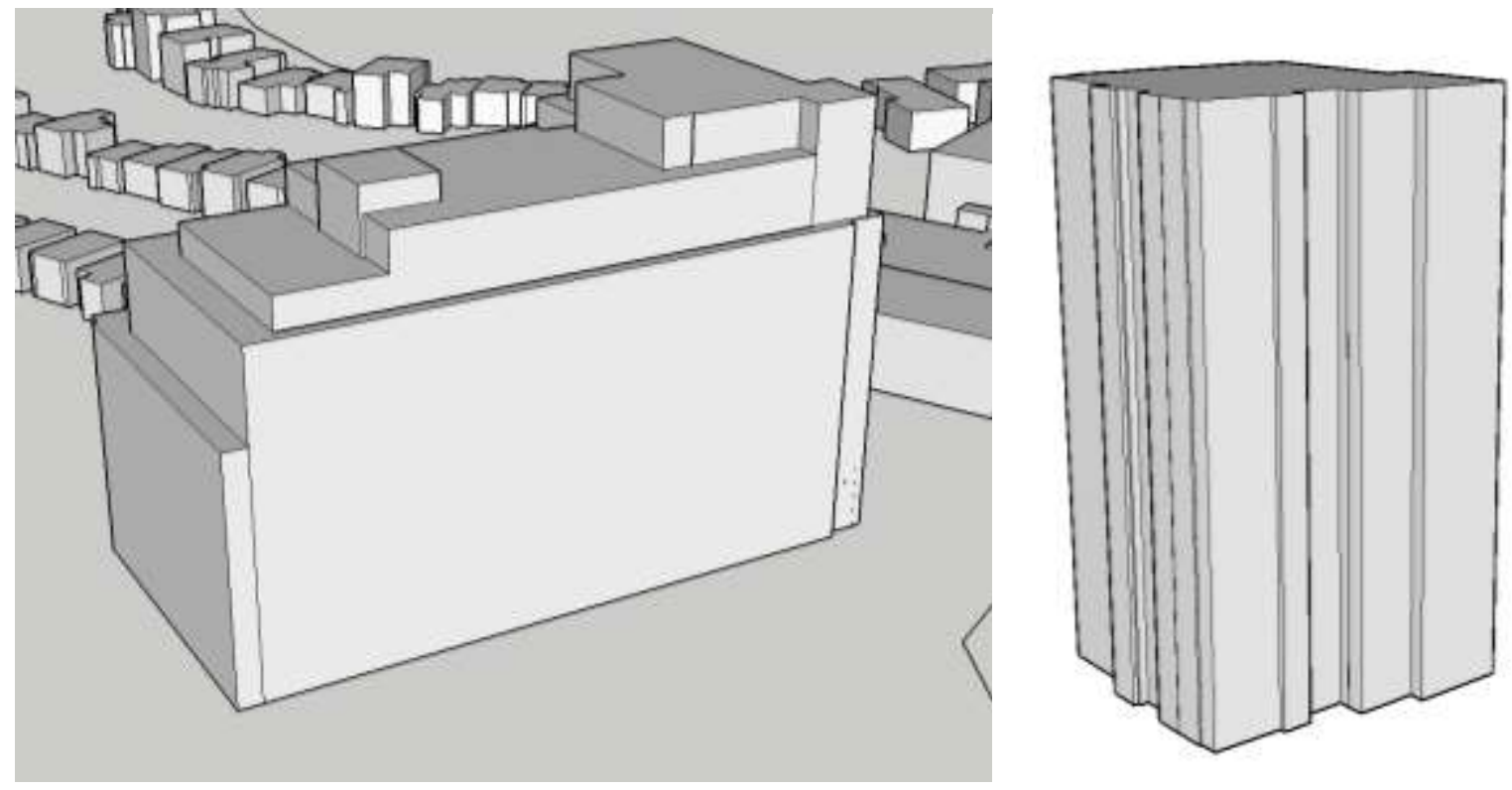

Figure 5-4. Example of buildings with low surface volume to area ratios (left), and high surface area to volume ratios (right).

Within the buildings studied, the majority of the buildings followed a pattern of heating EUI decreasing as surface area to volume ratio increases. This is contrary to what would be expected when examining surface area's effect on heating EUI, as a larger surface area would generally lead to increased EUI through additional heating needed to account for the heat loss through the envelope. When examining the effect of the surface area to volume ratio on heating EUI, an $R^{2}$ value of 0.236522 was returned, with a $p$ value of 0.052 . The resulting coefficient is - 
9.45, indicating that as surface area to volume ratio increased, EUI decreased by 9.45 $\mathrm{ekWh} / \mathrm{m}^{2}$.

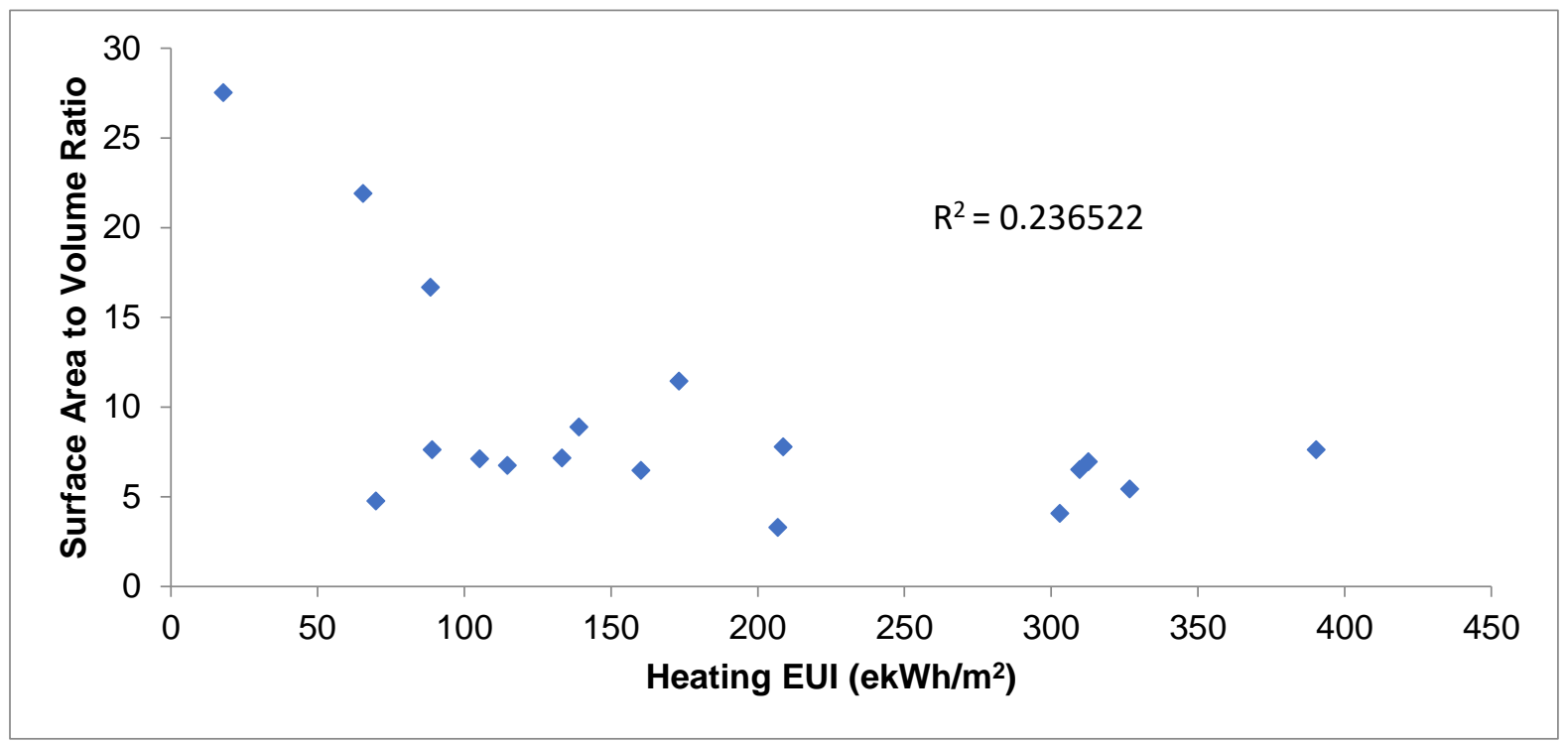

Figure 5-5. Surface Area to Volume Ratio's Effect on Heating EUI

The relationship between cooling EUI and surface area to volume ratio was also explored.

However, the regression model resulted in an $R^{2}$ of 0.044 . This is presumably because Toronto is not a cooling dominated climate, and that cooling is less of a function of the envelope than heating is.

Examination of the number of floors of the buildings is also tied to their surface area to volume ratio. Simple linear regression of this variable against total EUI returned an $R^{2}$ value of 0.104342 , however the $p$ value was rather high, at 0.177 , and therefore this correlation may not be very statistically significant.

\subsubsection{Envelope Category and Wall RSI}

The influence of envelope categories and wall RSI were examined both with individual regression models and as part of larger multivariate regression, to determine what impact, if any, this had on energy use. The subsequent $p$ values returned from the statistical analysis 
were much higher than expected, suggesting that there was no significant correlation between these attributes and energy use within the group of building examined. This does not necessarily lead to the conclusion that envelope category and RSI are not a factor, however, as the 19 buildings within this case study were predominantly of one type of envelope (Precast/Stucco) and therefore complete comparison of all three envelope types was extremely limited. In order to further evaluate the impact of the two variables, envelope category and wall RSI, a large sample of buildings with a more even distribution of features would be necessary.

\subsubsection{Impact of Conditioning and Base Loads}

One possible explanation for a higher than anticipated EUI for certain buildings is that they simply have higher conditioning loads. The average heating EUI for the sample was 176.7 $\mathrm{ekWh} / \mathrm{m}^{2}$. Using linear regression, the relationship between EUI and heating loads as a percentage of total EUI was investigated. 


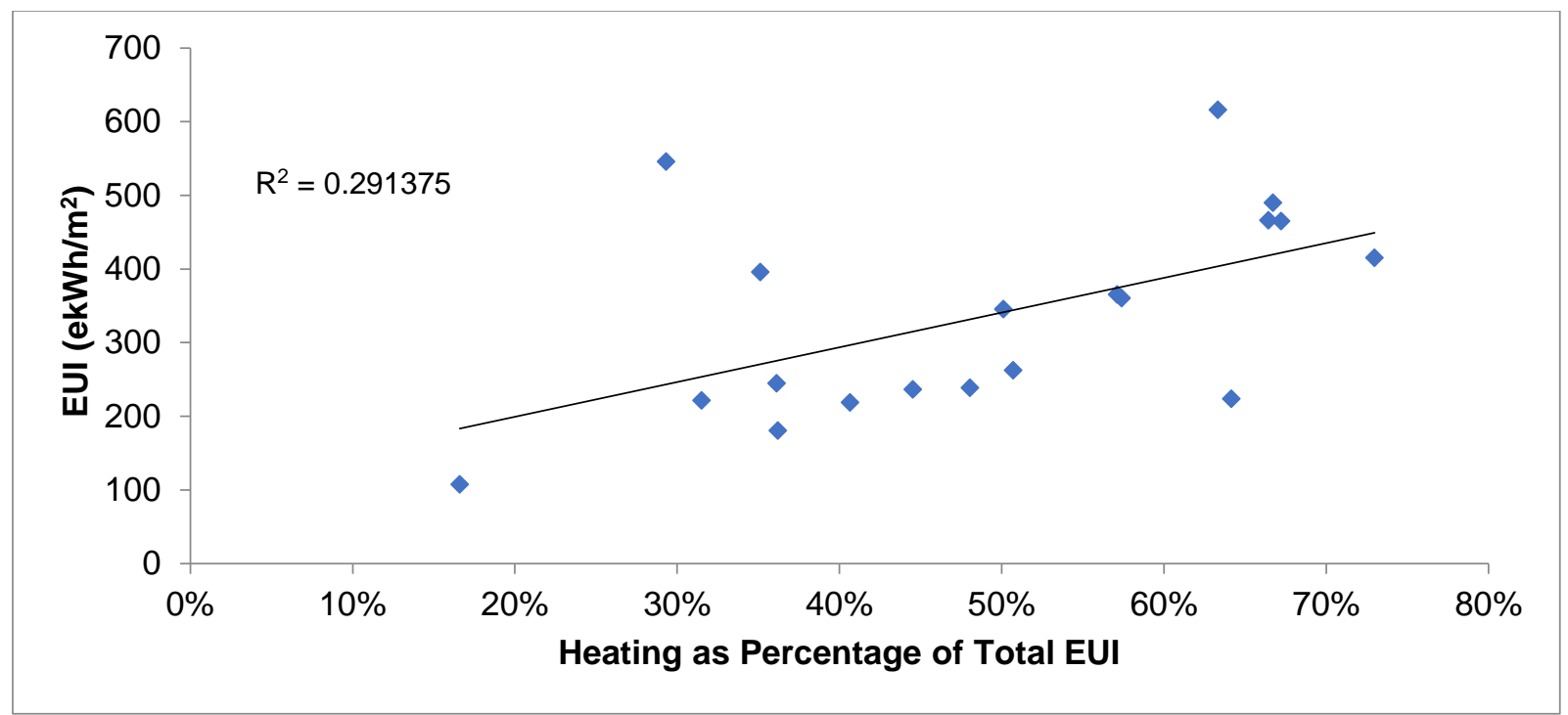

Figure 5-6. Heating as Percentage of Total EUI vs EUI

As seen in seen in Figure 5-6 above, buildings in which heating accounted for a larger percentage of their total EUI had higher EUls on average. This correlation was fairly significant, with an $R^{2}$ value of 0.29 , and a $p$-value of 0.0171 . An increase in heating as a percentage of EUI was found to result in an average of $471.55 \mathrm{ekWh} / \mathrm{m}^{2}$ increase in EUI.

The average cooling EUI for the sample was $55.8 \mathrm{ekWh} / \mathrm{m}^{2}$. Using linear regression, the relationship between EUI and cooling loads as a percentage of total EUI was investigated. A less significant correlation between cooling loads and EUI was established, however, indicating that cooling load is not as influential as heating loads are on the overall EUI of a building. This makes sense given the heating-dominated climate that is the GTA.

Base loads as a percentage of EUI were statistically insignificant when examined in single variable regression, however a multi-variate regression of heating EUI, cooling EUI, and baseload EUI as percentages of total EUI revealed an $R^{2}$ of 0.615 . The p-value of heating EUI and baseload EUI were both significant, at 0.0007 and 0.004 respectively; whereas the p-value for cooling EUI remained high, at 0.195 . This leads to the conclusion that within this particular 
set of buildings, cooling EUI is a less significant contributing factor to overall EUI when compared to heating EUI and base load EUI.

Upon further investigation into the conditioning loads, the fact that a number of buildings had both heating and cooling loads during the heating season was discovered. The following chart represents buildings which had over 1000 ekWh of cooling during the heating season (October to May), or over 1000 ekWh of heating during the cooling season (June to September).

Table 5-5. Investigation into Cooling and Heating Load Inefficiency by Building

\begin{tabular}{|c|c|c|}
\hline Building No. & Cooling During Heating & Heating During Cooling \\
\hline 001 & Yes & No \\
\hline 002 & No & Yes \\
\hline 003 & No & Yes \\
\hline 004 & Yes & Yes \\
\hline 005 & No & No \\
\hline $006 \mathrm{~A}$ & No & No \\
\hline 006B & No & No \\
\hline 007 & No & No \\
\hline $008 \mathrm{~A}$ & Yes & Yes \\
\hline 008B & Yes & Yes \\
\hline 009 & Yes & Yes \\
\hline 010 & Yes & Yes \\
\hline 011 & Yes & Yes \\
\hline $014 \mathrm{~A}$ & Yes & Yes \\
\hline 014B & Yes & Yes \\
\hline 015A & Yes & Yes \\
\hline 015B & Yes & Yes \\
\hline 016 & No & No \\
\hline 017 & Yes & Yes \\
\hline
\end{tabular}


The buildings which consistently only had one type of conditioning load per season are all within the lower half of the EUI spectrum for this sample, and are the buildings which are performing better than the TAF benchmark.

The categories of "Cooling" and "No Cooling" during the heating season were examined, using the simple linear regression model. As cooling may be working in competition with the heating systems, this may explain why heating EUI has become such a contributing factor to energy use as well.

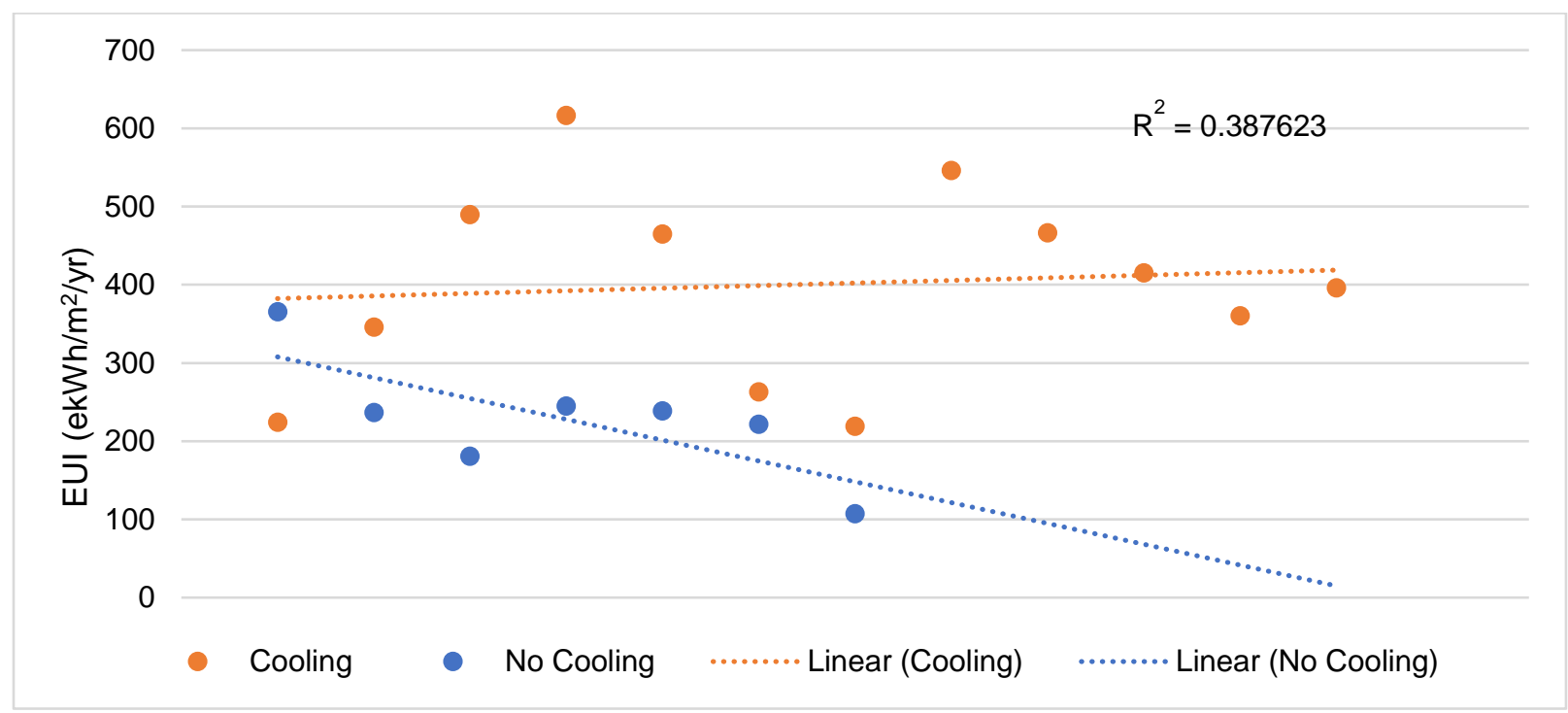

Figure 5-7. Cooling During the Heating Season 


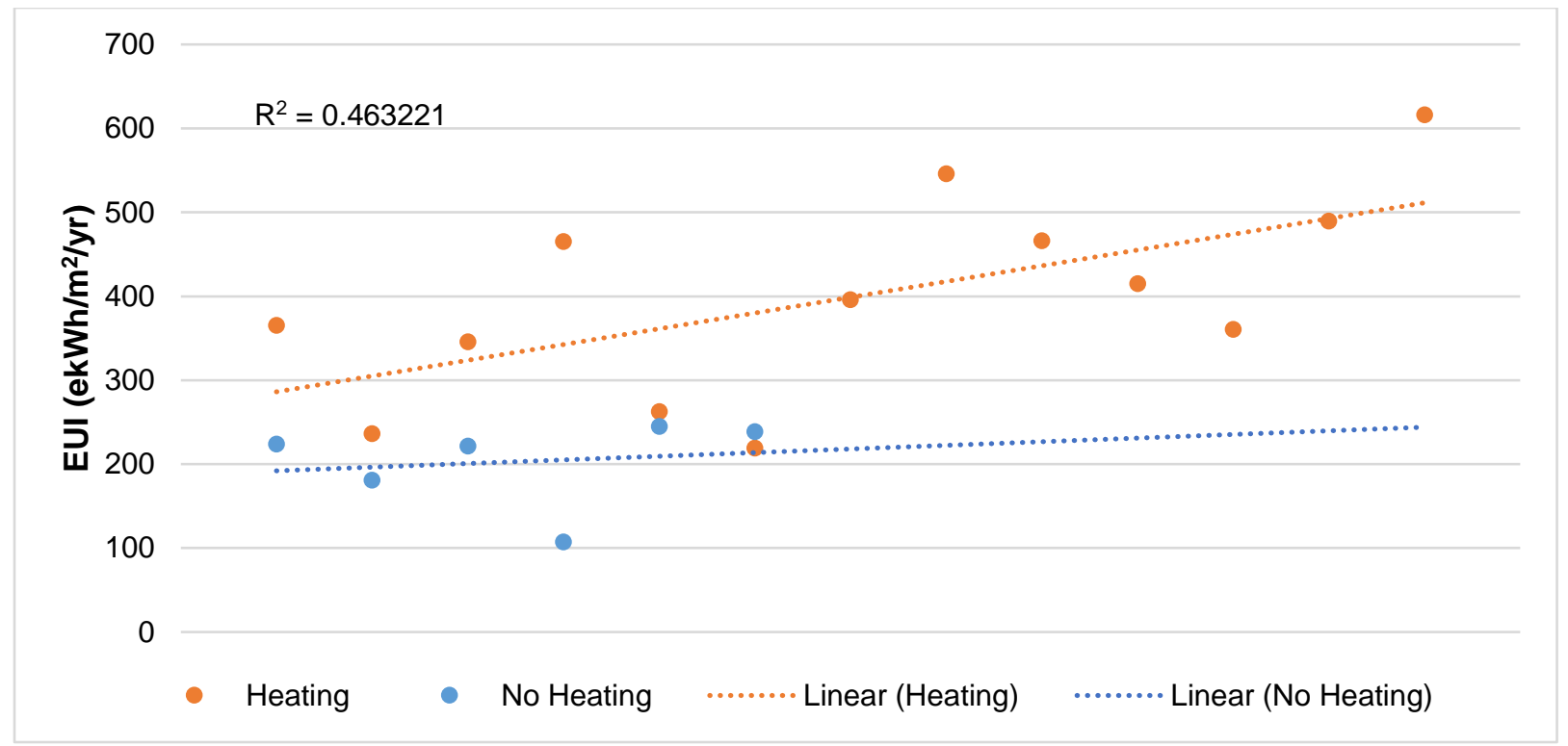

Figure 5-8. Heating in Cooling Season

Similarly, the categories of "Heating" and "No Heating" during the cooling season were examined in Figure 5-8.

Building 016, with the lowest total EUI also had the lowest heating EUI. It seems that although this building is sub-metered and units each have their own thermostat, the heating systems themselves are turned on or off depending on the season. For this reason, the building shows almost no heating loads between June to September, and almost no cooling loads between October to May. This is the case for a number of buildings within the study, and the result appears to be a much more energy efficient building.

A more in-depth analysis of the building's systems, setpoints, and occupant behaviour may reveal the reasoning behind these abnormal conditioning loads. Examining occupants thermal comfort, for example, may reveal that the building is overheating in the winter time, or that certain zones of the units are warm while others are cool, causing occupants to both heat and cool the space. This analysis is beyond the scope of this study, and is suggested for further works. 


\subsubsection{Boiler Efficiency}

A total of 15 of the 19 buildings had information available on their boiler efficiency, with efficiencies ranging between $85-95 \%$. Despite the correlation between conditioning loads and EUI, there was a very low correlation between boiler efficiency and energy use. The simple linear regression model revealed an $R^{2}$ value of 0.007166 and a $p$ value of 0.76 . Though surprising, this is similar to what has been seen in other studies on building energy use in Toronto, leading to the conclusion that boiler efficiency other factors may have larger impacts on building energy performance (Binkley et al., 2012). Moreover, as the boiler efficiencies stated are based on the manufacturer's maximum expected performance, not on in field performance data, the boilers may not be performing as efficiently as stated in the field.

\subsubsection{Chiller COP, Chiller Capacity and Cooling Tower Capacity}

There was a strong correlation between increased chiller and cooling tower capacity and increased EUI. The regression model for cooling tower capacity produced an $R^{2}$ of 0.31 and a $p$-value of 0.013 , and the model for chillers produced an $R^{2}$ of 0.27 and a $p$-value of 0.024 . However, the resulting coefficients for these variables were quite small, only contributing 0.30 $\mathrm{ekWh} / \mathrm{m}^{2}$ and $0.38 \mathrm{ekWh} / \mathrm{m}^{2}$ respectively on average.

Chiller COP information was only available for 12 of the 19 case study buildings, those buildings without a COP value have been removed to avoid skewing results. Examination of the variable chiller COP revealed that increasing chiller COP correlated with increased EUI, rather than decreasing it. Increasing chiller COP resulted in a $36.28 \mathrm{ekWh} / \mathrm{m}^{2}$ increase in EUI on average, within the regression model, however the $p$ value was quite high at 0.49 . 


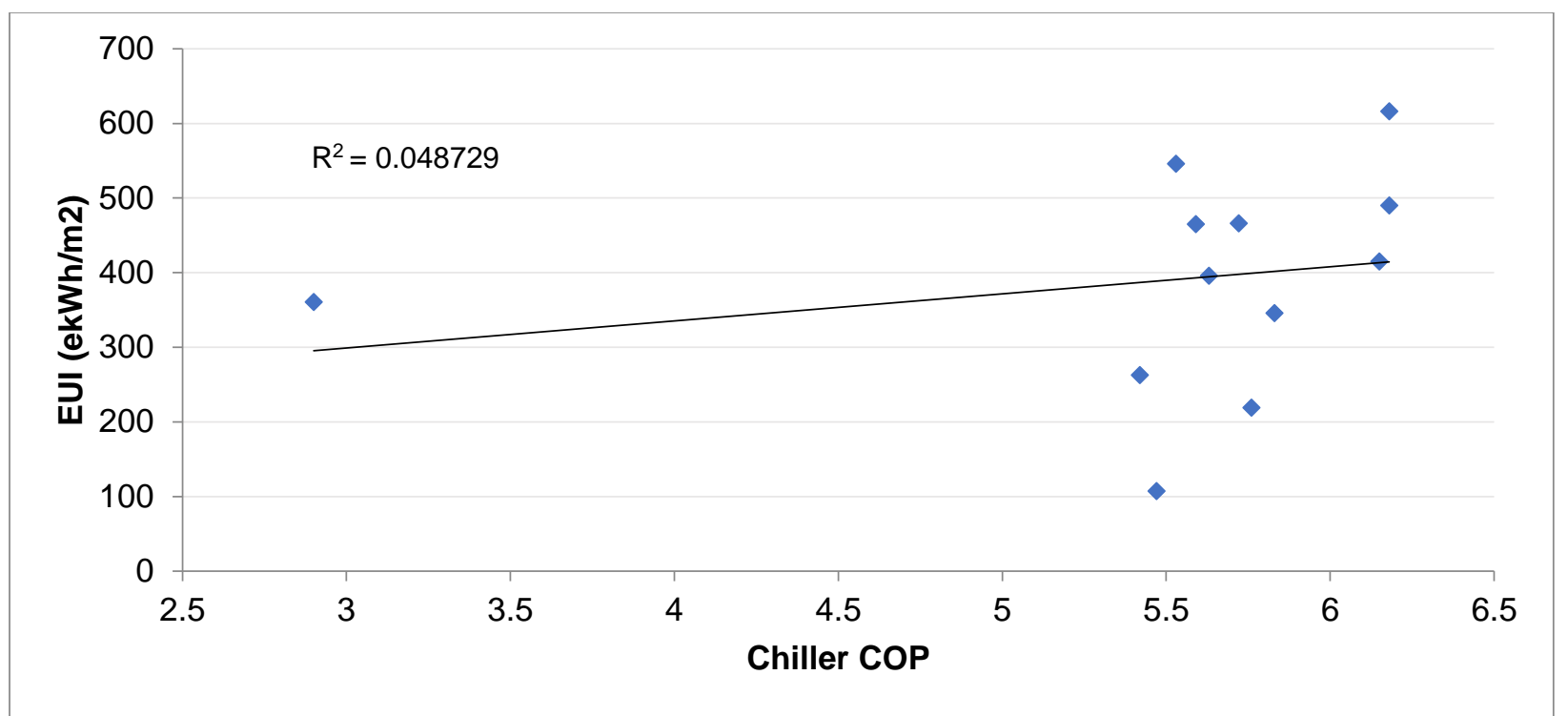

Figure 5-9. Relationship Between EUI and Chiller COP

This is the opposite of what would typically be predicted, as increasing the performance of a system should result in energy use reductions. However, the variable for chiller COP is based on the stated chiller COP taken from the modelling reports for these buildings, which was most likely derived from manufacturer white papers of predicted optimum performance. This may mean that the COP noted varies with actual installation in the field.

\subsubsection{Average Energy Use by Unit}

Another avenue of examination, in an attempt to understand such a large variation in EUI amongst these buildings, is considering occupant behaviour. The below comparison looked at the actual, non-weather normalized energy usage data for four separate months between September 2015 to June 2016. Average energy use by unit was examined against total EUI, however the linear regression returned no significant correlation.

It was also deduced that the standard deviation between suite energy uses was quite small on average for all buildings with the exception of 011 and 009 . This indicates that, unlike in other 
studies, where unit energy usage varied by a factor of 7 , the unit energy use within this sample is fairly consistent (Brown, Gorgolewski, et al., 2015).

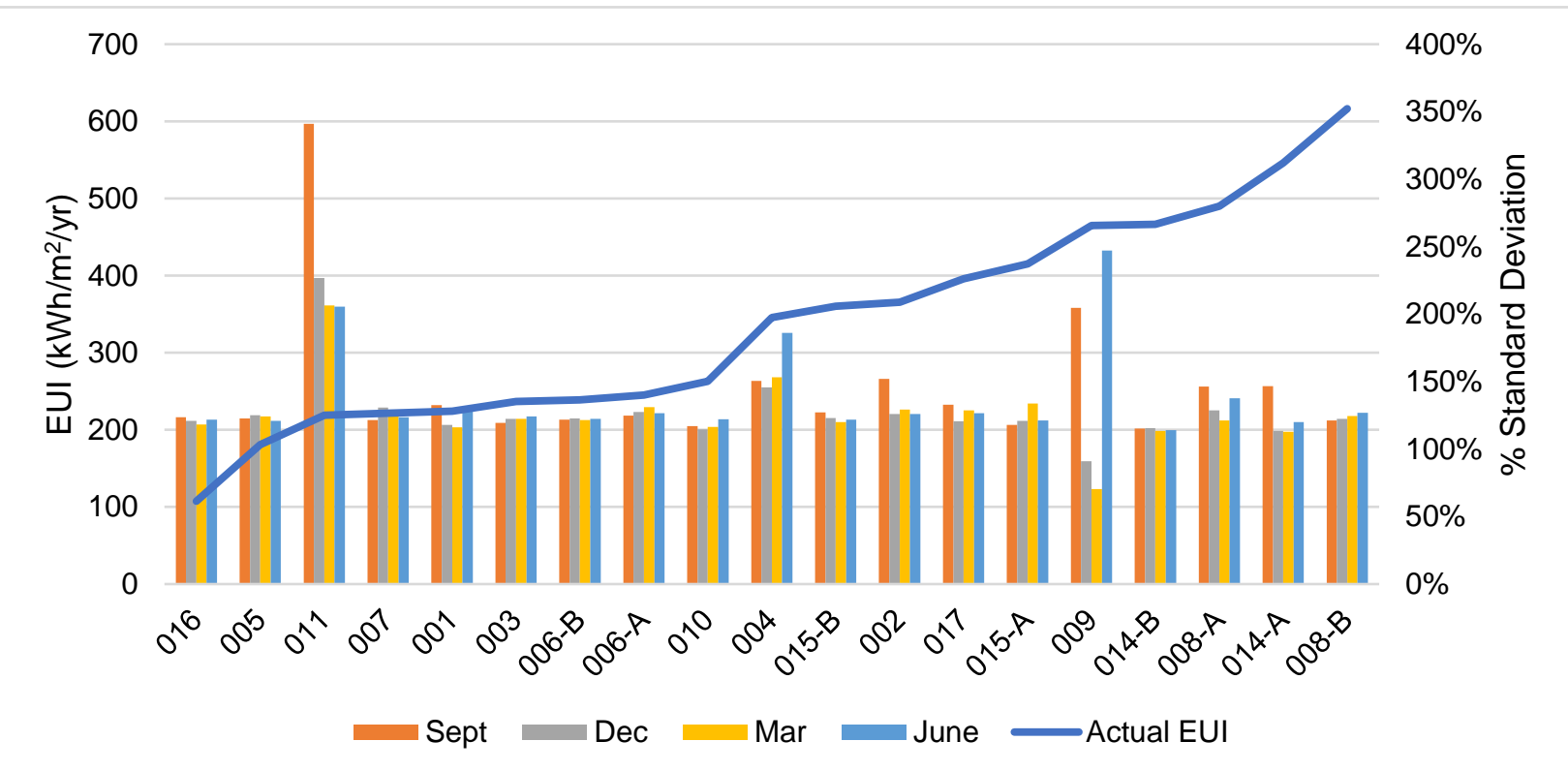

Figure 5-10. Standard Deviation of Suite Level Energy Use Over a 1 Year Period

Based upon these findings it is not believed that the variations in EUI across the case study sample are related to vast differences in specific occupant's behaviours at the suite level, but rather these variations are more deeply tied to the conditioning systems of each building.

\section{Conclusion}

As can be seen from this case study, LEED buildings within Toronto suffer from the same limitations that have been seen in the United States, namely that, despite touting itself as a building sustainability rating system, a relationship between LEED certification of buildings and energy use reductions is difficult to establish. Instead, LEED seems to produce a mixed batch of results, and despite the required modelling, the actual energy outcomes remain unpredictable. 
This study revealed that there was no clear correlation between LEED certification levels or the number of LEED EAc1 credits obtained by both LEED Gold and LEED Silver buildings within the GTA and their energy use intensity, based on real energy data gathered over a three-year period. In the majority of cases within the case study sample, buildings did not meet their targeting energy reductions as modelled. As LEED does not require the modelling of "nonregulated" loads - arguably one of the harder to model but also extremely important facets of energy use - the ability for LEED EAc1 credits to accurately predict energy use is extremely limited. This is compounded by the inherent uncertainty behind building energy modelling and building energy use prediction.

Moreover, when the case study sample was compared to building energy benchmarks of typical construction within the GTA, just under half of the sample was performing better than the average building. This does not bode well for LEED, and echoes some of the same concerns that Scofield (2013) discussed in their study of LEED building stock in New York City, namely, if a clear correlation between LEED and energy use reductions does not exist - if LEED buildings are no better than typical construction - then what is their benefit? This is especially when considering that LEED projects can, often times, come at a higher cost per square foot.

This study examined only buildings certified under the first iteration of LEED in Canada, LEED NC 1.0, and it is important to recognize that further improvements have been made to the system since then. There are also a number of changes on the horizon, the most important one being the introduction of energy benchmarking. This solves two problems, first, it takes care of the issue of awarding certifications to buildings based on modelling alone, and pushes the importance of proper building commissioning, ongoing system adjustments, and tenant education programs. A building is only as green as its occupants. Second, benchmarking involves the collection of important and, up until now, hard to find building energy data. This 
energy data can be used to fine tune building energy modelling as well as to better inform the CaGBC of the gaps within the LEED system, allowing them to investigate and correct them.

In order to improve LEED's ability to push the market towards greener buildings, changes should be made to the current process. Many of these changes are already underway, however from this case study it is clear that energy modelling alone is not sufficient enough verification of energy performance. Rather, energy use should continue to be monitored post-occupancy, to ensure targets are continuously met and that systems are being appropriately looked after.

More work needs to be put into understanding the impacts of residential occupancy on energy use prediction. One venue for this would be building occupancy surveys - to understand not only behavioural habitats of residents, but to identify any potential comfort issues or misunderstandings of building systems, and to help educate residents about their "green buildings" so that everyone can benefit from maximized energy savings and minimized negative environmental impacts. Best practices and knowledge sharing should be put forth and widely disseminated amongst the building community, to help facilitate a more robust understanding of the complex issue that occupancy poses amongst all stakeholders.

Moreover, evaluating the buildings based on a hypothetical MNECB base model unique to each building seems to have produced several buildings of similar EUI but difference levels of certification across the design modelling process. For this reason, LEED buildings should instead be required to meet a certain benchmark or threshold, such as a target EUI, which can apply to buildings of varying sizes while still maintaining integrity of the rating. Such a benchmark should be based upon real building energy data, so that it is both achievable and meaningful in the local context, to create actual energy reductions against existing building stock. 
However, it is important to recognize that this study was composed of only a small sample of buildings from the Greater Toronto Area, and therefore was limited in its ability to produce more in-depth correlations. Future research should be done to understand the limiting factors of LEED buildings - and LEED MURBs in particular - and to create mitigation plans for future builds. 


\section{Appendices}

\section{Appendix 1. Building Features Overview}

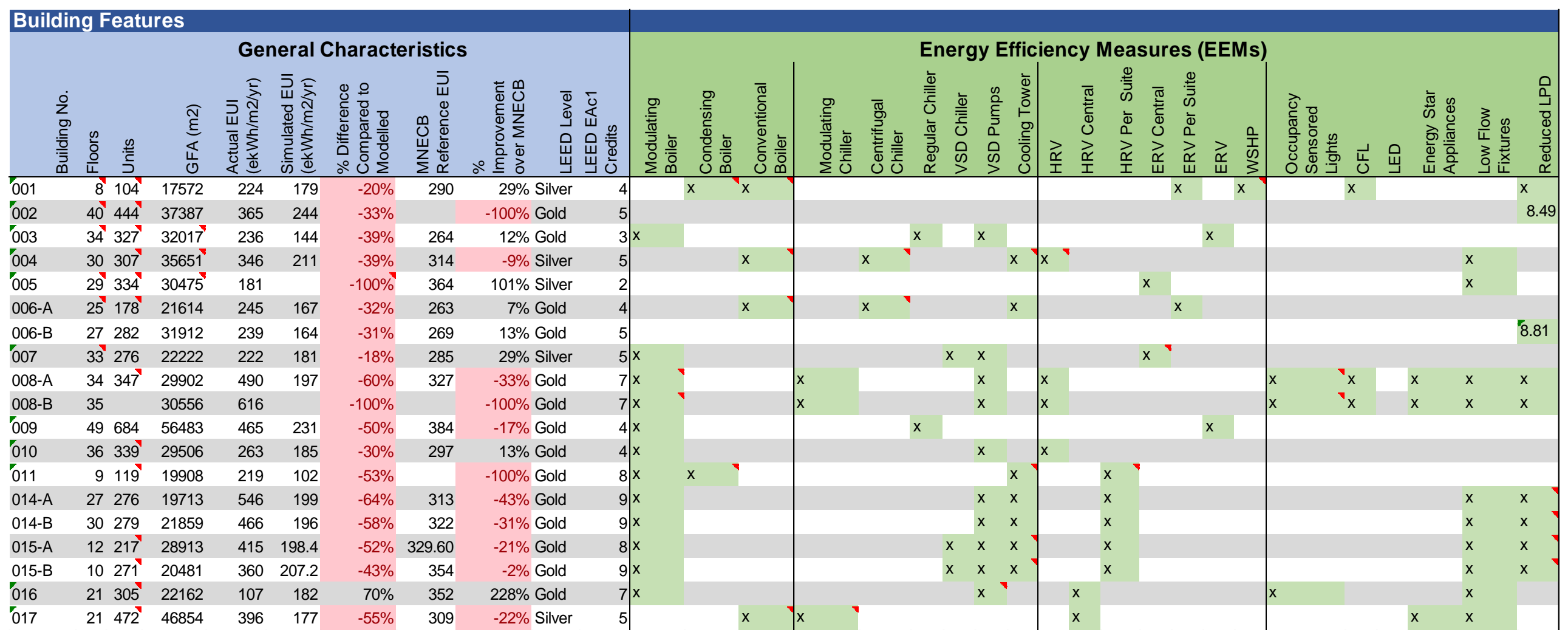




\section{Appendix 2. Outputs of Regression Models}

\begin{tabular}{lr}
\multicolumn{2}{l}{$\begin{array}{l}\text { SUMMARY } \\
\text { OUTPUT }\end{array}$} \\
\multicolumn{2}{c}{ Regression Statistics } \\
\hline Multiple R & 0.32302 \\
R Square & 0.104342 \\
Adjusted R Square & 0.051656 \\
Standard Error & 133.8429 \\
Observations & 19 \\
\hline
\end{tabular}

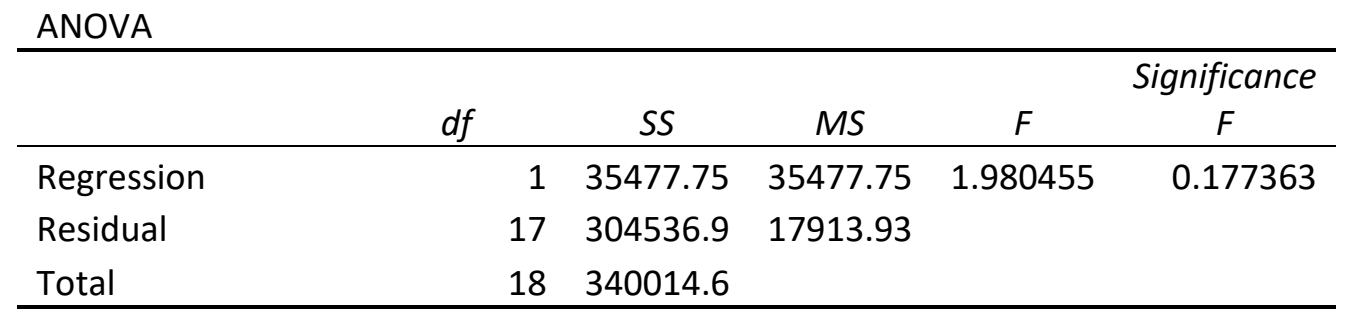

\begin{tabular}{lrccccccc}
\hline & \multicolumn{3}{c}{ Standard } & & & Upper & \multicolumn{1}{c}{ Lower } & \multicolumn{1}{c}{ Upper } \\
& Coefficients & Error & t Stat & P-value & Lower 95\% & \multicolumn{1}{c}{$95 \%$} & \multicolumn{9}{c}{$95.0 \%$} & \multicolumn{1}{c}{$95.0 \%$} \\
\hline Intercept & 223.2737 & 86.40911 & 2.583914 & 0.019311 & 40.96645 & 405.581 & 40.96645 & 405.581 \\
Floors & 4.177269 & 2.968315 & 1.407287 & 0.177363 & -2.08533 & 10.43987 & -2.08533 & 10.43987 \\
\hline
\end{tabular}


SUMMARY

OUTPUT

\begin{tabular}{lr}
\hline \multicolumn{2}{c}{ Regression Statistics } \\
\hline Multiple R & 0.306075 \\
R Square & 0.093682 \\
Adjusted R Square & 0.040369 \\
Standard Error & 134.6371 \\
Observations & 19 \\
\hline
\end{tabular}

ANOVA

\begin{tabular}{|c|c|c|c|c|c|}
\hline & $d f$ & SS & $M S$ & $F$ & $\begin{array}{c}\text { Significance } \\
F\end{array}$ \\
\hline Regression & 1 & 31853.23 & 31853.23 & 1.757212 & 0.202512 \\
\hline Residual & 17 & 308161.4 & 18127.14 & & \\
\hline Total & 18 & 340014.6 & & & \\
\hline
\end{tabular}

\begin{tabular}{lcccccccc}
\hline & \multicolumn{3}{c}{ Standard } & & & Upper & Lower & Upper \\
& Coefficients & Error & t Stat & P-value & Lower 95\% & $95 \%$ & $95.0 \%$ & $95.0 \%$ \\
\hline Intercept & 262.2167 & 64.277 & 4.079479 & 0.000781 & 126.604 & 397.8293 & 126.604 & 397.8293 \\
& & & & & & & - \\
Units & 0.223193 & 0.168372 & 1.325599 & 0.202512 & -0.13204 & 0.578427 & 0.13204 & 0.578427 \\
\hline
\end{tabular}




\section{SUMMARY OUTPUT}

\begin{tabular}{lr}
\hline \multicolumn{2}{c}{ Regression Statistics } \\
\hline Multiple R & 0.283023 \\
R Square & 0.080102 \\
Adjusted R Square & 0.02599 \\
Standard Error & 135.642 \\
Observations & 19 \\
\hline
\end{tabular}

ANOVA

\begin{tabular}{|c|c|c|c|c|c|}
\hline & $d f$ & SS & $M S$ & $F$ & $\begin{array}{c}\text { Significance } \\
F\end{array}$ \\
\hline Regression & 1 & 27235.89 & 27235.89 & 1.480312 & 0.240348 \\
\hline Residual & 17 & 312778.7 & 18398.75 & & \\
\hline Total & 18 & 340014.6 & & & \\
\hline
\end{tabular}

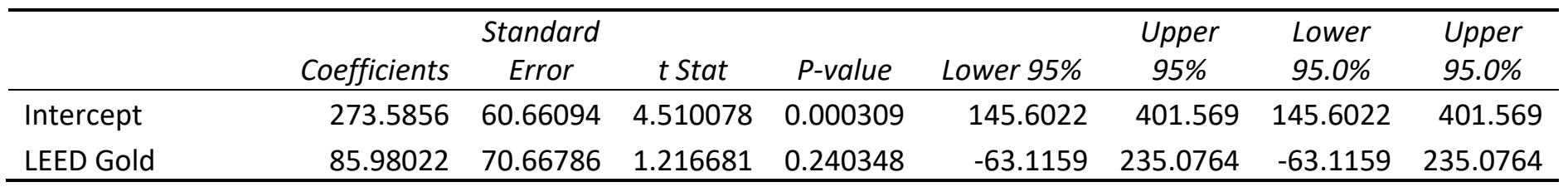


SUMMARY

OUTPUT

\begin{tabular}{lr}
\hline \multicolumn{2}{c}{ Regression Statistics } \\
\hline Multiple R & 0.480396 \\
R Square & 0.230781 \\
Adjusted R Square & 0.185532 \\
Standard Error & 124.0365 \\
Observations & 19 \\
\hline
\end{tabular}

ANOVA

\begin{tabular}{|c|c|c|c|c|c|}
\hline & $d f$ & SS & $M S$ & $F$ & $\begin{array}{c}\text { Significance } \\
F\end{array}$ \\
\hline Regression & 1 & 78468.78 & 78468.78 & 5.100327 & 0.037356 \\
\hline Residual & 17 & 261545.8 & 15385.05 & & \\
\hline Total & 18 & 340014.6 & & & \\
\hline
\end{tabular}

\begin{tabular}{lrccccccc}
\hline & \multicolumn{3}{c}{ Standard } & & & Upper & Lower & Upper \\
& Coefficients & Error & t Stat & P-value & Lower 95\% & 95\% & 95.0\% & $95.0 \%$ \\
\hline Intercept & 159.0968 & 83.73117 & 1.900091 & 0.074519 & -17.5605 & 335.7542 & -17.5605 & 335.7542 \\
EAc1 Credits & 30.71827 & 13.60184 & 2.25839 & 0.037356 & 2.020889 & 59.41564 & 2.020889 & 59.41564 \\
\hline
\end{tabular}


SUMMARY

OUTPUT

\begin{tabular}{lr}
\hline \multicolumn{2}{c}{ Regression Statistics } \\
\hline Multiple R & 0.330718 \\
R Square & 0.109375 \\
Adjusted R Square & 0.056985 \\
Standard Error & 133.4664 \\
Observations & 19 \\
\hline
\end{tabular}

ANOVA

\begin{tabular}{|c|c|c|c|c|c|}
\hline & & & & & Significance \\
\hline & $d f$ & SS & $M S$ & $F$ & $F$ \\
\hline Regression & 1 & 37188.94 & 37188.94 & 2.087709 & 0.166669 \\
\hline Residual & 17 & 302825.7 & 17813.28 & & \\
\hline Total & 18 & 340014.6 & & & \\
\hline
\end{tabular}

\begin{tabular}{lrcrrrrrr}
\hline & \multicolumn{3}{c}{ Standard } & & & Upper & Lower & Upper \\
& Coefficients & Error & t Stat & P-value & Lower 95\% & \multicolumn{1}{c}{$95 \%$} & \multicolumn{1}{c}{$95.0 \%$} & $95.0 \%$ \\
\hline Intercept & 310.5001 & 35.67039 & 8.7047 & $1.14 \mathrm{E}-07$ & 235.2421 & 385.758 & 235.2421 & 385.758 \\
Spandrel & 100.4696 & 69.53439 & 1.444891 & 0.166669 & -46.2352 & 247.1743 & -46.2352 & 247.1743 \\
\hline
\end{tabular}


SUMMARY

OUTPUT

\begin{tabular}{lr}
\hline \multicolumn{2}{c}{ Regression Statistics } \\
\hline Multiple R & 0.113696 \\
R Square & 0.012927 \\
Adjusted R Square & -0.04514 \\
Standard Error & 140.5073 \\
Observations & 19 \\
\hline
\end{tabular}

ANOVA

\begin{tabular}{|c|c|c|c|c|c|}
\hline & & & & & Significance \\
\hline & $d f$ & SS & $M S$ & $F$ & $F$ \\
\hline Regression & 1 & 4395.299 & 4395.299 & 0.222633 & 0.64304 \\
\hline Residual & 17 & 335619.3 & 19742.31 & & \\
\hline Total & 18 & 340014.6 & & & \\
\hline
\end{tabular}

\begin{tabular}{lrccccccc}
\hline & \multicolumn{3}{c}{ Standard } & & & Upper & Lower & Upper \\
& Coefficients & Error & t Stat & P-value & Lower 95\% & $95 \%$ & $95.0 \%$ & $95.0 \%$ \\
\hline Intercept & 356.8535 & 53.10678 & 6.719546 & $3.6 \mathrm{E}-06$ & 244.8079 & 468.899 & 244.8079 & 468.899 \\
Precast Stucco & -31.5305 & 66.82457 & -0.47184 & 0.64304 & -172.518 & 109.457 & -172.518 & 109.457 \\
\hline
\end{tabular}


SUMMARY

OUTPUT

\begin{tabular}{lr}
\hline \multicolumn{2}{c}{ Regression Statistics } \\
\hline Multiple R & 0.413213 \\
R Square & 0.170745 \\
Adjusted R Square & 0.121965 \\
Standard Error & 128.7859 \\
Observations & 19 \\
\hline
\end{tabular}

ANOVA

\begin{tabular}{|c|c|c|c|c|c|}
\hline & & & & & Significance \\
\hline & $d f$ & SS & $M S$ & $F$ & $F$ \\
\hline Regression & 1 & 58055.7 & 58055.7 & 3.500322 & 0.078672 \\
\hline Residual & 17 & 281958.9 & 16585.82 & & \\
\hline Total & 18 & 340014.6 & & & \\
\hline
\end{tabular}

\begin{tabular}{lrrrrrrrr}
\hline & \multicolumn{3}{c}{ Standard } & & & Upper & Lower & Upper \\
& Coefficients & \multicolumn{1}{c}{ Error } & \multicolumn{1}{c}{ t Stat } & P-value & Lower 95\% & 95\% & \multicolumn{1}{c}{$95.0 \%$} & $95.0 \%$ \\
\hline Intercept & 272.1212 & 45.53271 & 5.97639 & $1.5 \mathrm{E}-05$ & 176.0556 & 368.1868 & 176.0556 & 368.1868 \\
HRV & 111.9587 & 59.8417 & 1.870915 & 0.078672 & -14.2962 & 238.2137 & -14.2962 & 238.2137 \\
\hline
\end{tabular}


SUMMARY

OUTPUT

\begin{tabular}{lr}
\hline \multicolumn{2}{c}{ Regression Statistics } \\
\hline Multiple R & 0.451784856 \\
R Square & 0.204109556 \\
Adjusted R Square & 0.157292471 \\
Standard Error & 126.1685119 \\
Observations & 19 \\
\hline
\end{tabular}

ANOVA

\begin{tabular}{|c|c|c|c|c|c|c|}
\hline & $d f$ & & SS & $M S$ & $F$ & $\begin{array}{c}\text { Significance } \\
F\end{array}$ \\
\hline Regression & & 1 & 69400.23 & 69400.23 & 4.359724 & 0.052157 \\
\hline Residual & & 17 & 270614.4 & 15918.49 & & \\
\hline Total & & 18 & 340014.6 & & & \\
\hline
\end{tabular}

\begin{tabular}{lcccccccc}
\hline & \multicolumn{3}{c}{ Standard } & & & Upper & Lower & Upper \\
& Coefficients & Error & t Stat & P-value & Lower 95\% & 95\% & $95.0 \%$ & $95.0 \%$ \\
\hline Intercept & 420.516045 & 49.39628 & 8.513111 & $1.55 \mathrm{E}-07$ & 316.299 & 524.7331 & 316.299 & 524.7331 \\
SV & - & & & & & & - & \\
& 9.450295393 & 4.526014 & -2.088 & 0.052157 & -18.9994 & 0.09876 & 18.9994 & 0.09876 \\
\hline
\end{tabular}


SUMMARY

OUTPUT

\begin{tabular}{lr}
\hline \multicolumn{2}{c}{ Regression Statistics } \\
\hline Multiple R & 0.098952 \\
R Square & 0.009792 \\
Adjusted R Square & -0.04846 \\
Standard Error & 140.7303 \\
Observations & 19 \\
\hline
\end{tabular}

ANOVA

\begin{tabular}{|c|c|c|c|c|c|}
\hline & $d f$ & SS & $M S$ & $F$ & $\begin{array}{c}\text { Significance } \\
F\end{array}$ \\
\hline Regression & 1 & 3329.278 & 3329.278 & 0.168103 & 0.686924 \\
\hline Residual & 17 & 336685.3 & 19805.02 & & \\
\hline Total & 18 & 340014.6 & & & \\
\hline
\end{tabular}

\begin{tabular}{lrccccccc}
\hline & \multicolumn{3}{c}{ Standard } & & Upper & Lower & Upper \\
& Coefficients & Error & t Stat & P-value & Lower 95\% & \multicolumn{1}{c}{$95 \%$} & \multicolumn{1}{c}{$95.0 \%$} & $95.0 \%$ \\
\hline Intercept & 317.328 & 57.70886 & 5.498774 & $3.91 \mathrm{E}-05$ & 195.5729 & 439.083 & 195.5729 & 439.083 \\
Wall RSI & 10.40832 & 25.38594 & 0.410003 & 0.686924 & -43.1513 & 63.96796 & -43.1513 & 63.96796 \\
\hline
\end{tabular}


SUMMARY

OUTPUT

\begin{tabular}{lr}
\hline \multicolumn{2}{c}{ Regression Statistics } \\
\hline Multiple R & 0.555267 \\
R Square & 0.308322 \\
Adjusted R Square & 0.267635 \\
Standard Error & 117.6187 \\
Observations & 19 \\
\hline
\end{tabular}

ANOVA

\begin{tabular}{|c|c|c|c|c|c|}
\hline & $d f$ & SS & $M S$ & $F$ & $\begin{array}{c}\text { Significance } \\
F\end{array}$ \\
\hline Regression & 1 & 104833.8 & 104833.8 & 7.577893 & 0.013588 \\
\hline Residual & 17 & 235180.8 & 13834.16 & & \\
\hline Total & 18 & 340014.6 & & & \\
\hline
\end{tabular}

\begin{tabular}{lrrrrrrrr}
\hline & \multicolumn{3}{c}{ Standard } & & & Upper & Lower & Upper \\
& Coefficients & \multicolumn{1}{c}{ Error } & \multicolumn{1}{c}{ t Stat } & P-value & Lower 95\% & $95 \%$ & $95.0 \%$ & $95.0 \%$ \\
\hline Intercept & 242.5562 & 43.63102 & 5.55926 & $3.46 \mathrm{E}-05$ & 150.5028 & 334.6095 & 150.5028 & 334.6095 \\
Chiller COP & 27.02314 & 9.81661 & 2.752797 & 0.013588 & 6.311901 & 47.73437 & 6.311901 & 47.73437 \\
\hline
\end{tabular}


SUMMARY

OUTPUT

\begin{tabular}{lr}
\hline \multicolumn{2}{c}{ Regression Statistics } \\
\hline Multiple R & 0.326354 \\
R Square & 0.106507 \\
Adjusted R Square & 0.053949 \\
Standard Error & 133.6811 \\
Observations & 19 \\
\hline
\end{tabular}

ANOVA

\begin{tabular}{|c|c|c|c|c|c|}
\hline & & & & & Significance \\
\hline & $d f$ & SS & $M S$ & $F$ & $F$ \\
\hline Regression & 1 & 36213.92 & 36213.92 & 2.026449 & 0.172676 \\
\hline Residual & 17 & 303800.7 & 17870.63 & & \\
\hline Total & 18 & 340014.6 & & & \\
\hline
\end{tabular}

\begin{tabular}{lrcccrcrc}
\hline & \multicolumn{3}{c}{ Standard } & & Upper & Lower & Upper \\
& Coefficients & Error & t Stat & P-value & Lower 95\% & \multicolumn{1}{c}{$95 \%$} & \multicolumn{1}{c}{$95.0 \%$} & $95.0 \%$ \\
\hline Intercept & 252.5509 & 66.74427 & 3.783859 & 0.001482 & 111.7328 & 393.369 & 111.7328 & 393.369 \\
Boiler Efficiency & 122.6765 & 86.17745 & 1.423534 & 0.172676 & -59.142 & 304.495 & -59.142 & 304.495 \\
\hline
\end{tabular}


SUMMARY

OUTPUT

\begin{tabular}{lr}
\hline \multicolumn{2}{c}{ Regression Statistics } \\
\hline Multiple R & 0.557848501 \\
R Square & 0.311194951 \\
Adjusted R Square & 0.270677006 \\
Standard Error & 117.3741598 \\
Observations & 19 \\
\hline
\end{tabular}

ANOVA

\begin{tabular}{|c|c|c|c|c|c|c|}
\hline & $d f$ & & SS & $M S$ & $F$ & $\begin{array}{c}\text { Significance } \\
F\end{array}$ \\
\hline Regression & & 1 & 105810.8 & 105810.8 & 7.680423 & $0.01306 \mathrm{~s}$ \\
\hline Residual & & 17 & 234203.8 & 13776.69 & & \\
\hline Total & & 18 & 340014.6 & & & \\
\hline
\end{tabular}

\begin{tabular}{|c|c|c|c|c|c|c|c|c|}
\hline & \multicolumn{3}{|c|}{ Standard } & \multirow[b]{2}{*}{ P-value } & \multirow[b]{2}{*}{ Lower 95\% } & Upper & \multirow{2}{*}{$\begin{array}{l}\text { Lower } \\
95.0 \%\end{array}$} & \multirow{2}{*}{$\begin{array}{l}\text { Upper } \\
95.0 \%\end{array}$} \\
\hline & Coefficients & Error & t Stat & & & $95 \%$ & & \\
\hline $\begin{array}{l}\text { Intercept } \\
\text { Cooling Tower }\end{array}$ & 237.2150732 & 44.94366 & 5.278054 & $6.15 \mathrm{E}-05$ & 142.3922 & 332.0379 & 142.3922 & 332.0379 \\
\hline Capacity & 0.305134189 & 0.110103 & 2.771358 & 0.013069 & 0.072838 & 0.537431 & 0.072838 & 0.537431 \\
\hline
\end{tabular}


SUMMARY OUTPUT

\begin{tabular}{lr}
\hline \multicolumn{2}{c}{ Regression Statistics } \\
\hline Multiple R & 0.516363 \\
R Square & 0.26663 \\
Adjusted R Square & 0.223491 \\
Standard Error & 121.1116 \\
Observations & 19 \\
\hline
\end{tabular}

ANOVA

\begin{tabular}{|c|c|c|c|c|c|}
\hline & & & & $E$ & $\begin{array}{c}\text { Significance } \\
F\end{array}$ \\
\hline & aJ & 005010 & MIS & 6180667 & $r$ \\
\hline Regression & 1 & 90658.18 & 90658.18 & 6.180667 & 0.02361 \\
\hline Residual & 17 & 249356.4 & 14668.03 & & \\
\hline Total & 18 & 340014.6 & & & \\
\hline
\end{tabular}

\begin{tabular}{|c|c|c|c|c|c|c|c|c|}
\hline & & Standard & & & & Upper & Lower & Upper \\
\hline & Coefficients & Error & t Stat & P-value & Lower 95\% & $95 \%$ & $95.0 \%$ & $95.0 \%$ \\
\hline Intercept & 243.5647 & 46.71898 & 5.2134 & 7.03E-05 & 144.9963 & 342.1332 & 144.9963 & 342.1332 \\
\hline Chiller Capacity & 0.381428 & 0.153425 & 2.486095 & 0.02361 & 0.057731 & 0.705126 & 0.057731 & 0.705126 \\
\hline
\end{tabular}


SUMMARY OUTPUT

\begin{tabular}{lr}
\hline \multicolumn{2}{c}{ Regression Statistics } \\
\hline Multiple R & 0.220748 \\
R Square & 0.048729 \\
Adjusted R Square & -0.0464 \\
Standard Error & 146.5331 \\
Observations & 12 \\
\hline
\end{tabular}

ANOVA

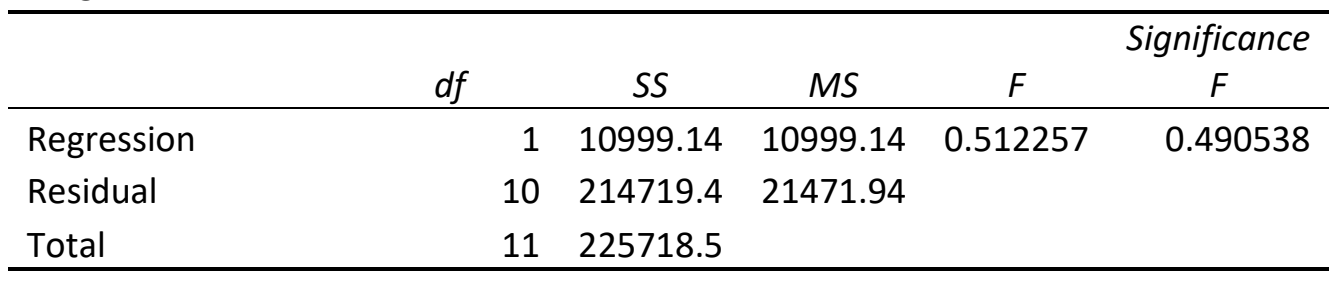

\begin{tabular}{lcccccccc}
\hline & \multicolumn{3}{c}{ Standard } & & & Upper & Lower & Upper \\
& Coefficients & Error & t Stat & P-value & Lower 95\% & $95 \%$ & $95.0 \%$ & $95.0 \%$ \\
\hline Intercept & 190.1809 & 283.5195 & 0.670786 & 0.517549 & -441.54 & 821.9016 & -441.54 & 821.9016 \\
& & & & & & & - & \\
Chiller COP & 36.28329 & 50.69474 & 0.715721 & 0.490538 & -76.6716 & 149.2382 & 76.6716 & 149.2382 \\
\hline
\end{tabular}


SUMMARY OUTPUT

\begin{tabular}{lr}
\hline \multicolumn{2}{c}{ Regression Statistics } \\
\hline Multiple R & 0.680604 \\
R Square & 0.463221 \\
Adjusted R Square & 0.431646 \\
Standard Error & 103.6148 \\
Observations & 19 \\
\hline
\end{tabular}

ANOVA

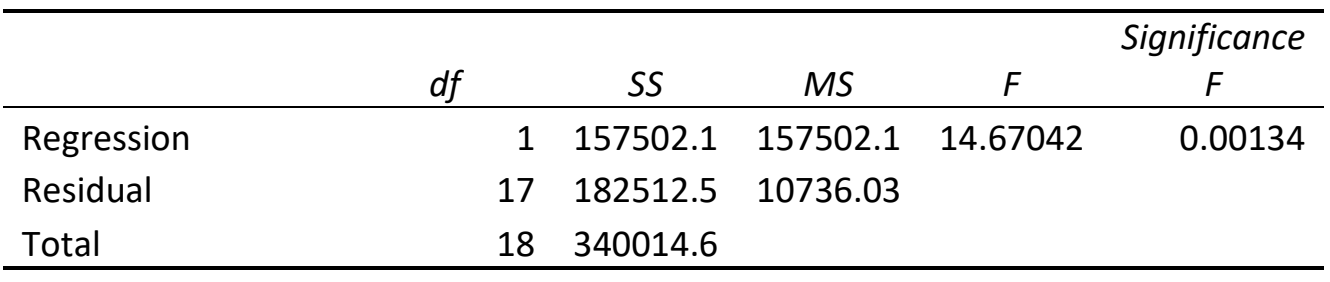

\begin{tabular}{lcccccccc}
\hline & \multicolumn{3}{c}{ Standard } & & & Upper & Lower & Upper \\
& Coefficients & Error & t Stat & P-value & Lower 95\% & 95\% & $95.0 \%$ & $95.0 \%$ \\
\hline $\begin{array}{l}\text { Intercept } \\
\begin{array}{l}\text { Heating during } \\
\text { Cooling Season }\end{array}\end{array}$ & 202.9217 & 42.30058 & 4.797137 & 0.000168 & 113.6753 & 292.1681 & 113.6753 & 292.1681 \\
\hline
\end{tabular}


SUMMARY OUTPUT

\begin{tabular}{lr}
\hline \multicolumn{2}{c}{ Regression Statistics } \\
\hline Multiple R & 0.622594 \\
R Square & 0.387623 \\
Adjusted R Square & 0.3516 \\
Standard Error & 110.671 \\
Observations & 19 \\
\hline
\end{tabular}

ANOVA

\begin{tabular}{lrrrrcc}
\hline & & & & & \multicolumn{2}{c}{ Significance } \\
& $d f$ & & SS & MS & $F$ & \multicolumn{1}{c}{. } \\
\hline Regression & 1 & 131797.4 & 131797.4 & 10.76066 & 0.004413 \\
Residual & 17 & 208217.2 & 12248.07 & & \\
Total & 18 & 340014.6 & & & \\
\hline
\end{tabular}

\begin{tabular}{|c|c|c|c|c|c|c|c|c|}
\hline & & Standard & & & & Upper & Lower & Upper \\
\hline & Coefficients & Error & t Stat & P-value & Lower 95\% & $95 \%$ & $95.0 \%$ & $95.0 \%$ \\
\hline Intercept & 227.8913 & 41.82971 & 5.448073 & $4.34 \mathrm{E}-05$ & 139.6383 & 316.1443 & 139.6383 & 316.1443 \\
\hline Cooling During Heating Season & 172.6595 & 52.63457 & 3.280345 & 0.004413 & 61.6103 & 283.7088 & 61.6103 & 283.7088 \\
\hline
\end{tabular}


SUMMARY OUTPUT

\begin{tabular}{lr}
\hline \multicolumn{2}{c}{ Regression Statistics } \\
\hline Multiple R & 0.816514 \\
R Square & 0.666695 \\
Adjusted R Square & 0.647089 \\
Standard Error & 81.64789 \\
Observations & 19 \\
\hline
\end{tabular}

ANOVA

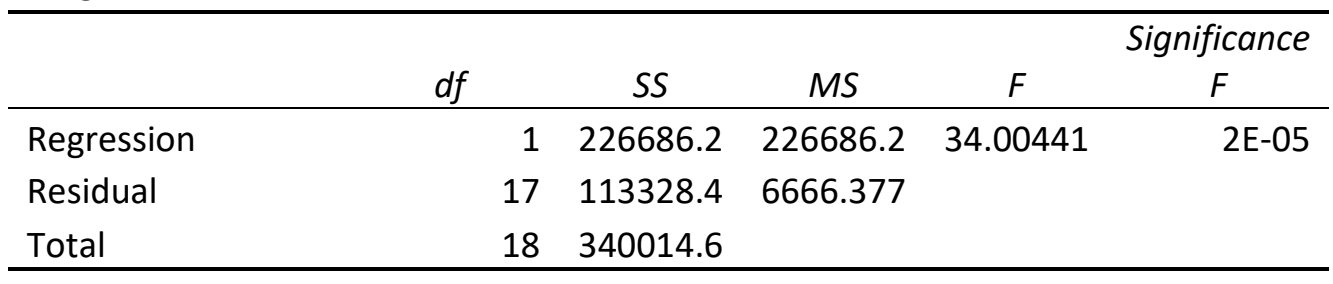

\begin{tabular}{lrrrrrrrr}
\hline & \multicolumn{3}{c}{ Standard } & & & Upper & Lower & Upper \\
& Coefficients & \multicolumn{1}{c}{ Error } & \multicolumn{1}{c}{ t Stat } & \multicolumn{1}{c}{ P-value } & Lower 95\% & \multicolumn{1}{c}{$95 \%$} & \multicolumn{1}{c}{$95.0 \%$} & $95.0 \%$ \\
\hline Intercept & 179.0906 & 32.91805 & 5.440499 & $4.41 \mathrm{E}-05$ & 109.6396 & 248.5416 & 109.6396 & 248.5416 \\
Base Load EUI & 1.246737 & 0.2138 & 5.83133 & $2 \mathrm{E}-05$ & 0.795659 & 1.697815 & 0.795659 & 1.697815 \\
\hline
\end{tabular}


SUMMARY

OUTPUT

\begin{tabular}{lr}
\hline \multicolumn{2}{c}{ Regression Statistics } \\
\hline Multiple R & 0.962279 \\
R Square & 0.925982 \\
Adjusted R Square & 0.911178 \\
Standard Error & 40.96123 \\
Observations & 19 \\
\hline
\end{tabular}

ANOVA

\begin{tabular}{|c|c|c|c|c|c|}
\hline & $d f$ & SS & $M S$ & $F$ & $\begin{array}{c}\text { Significance } \\
F\end{array}$ \\
\hline Regression & 3 & 314847.3 & 104949.1 & 62.55076454 & $1.04 \mathrm{E}-08$ \\
\hline Residual & 15 & 25167.34 & 1677.823 & & \\
\hline Total & 18 & 340014.6 & & & \\
\hline
\end{tabular}

\begin{tabular}{lrrrrrrrr}
\hline & \multicolumn{3}{c}{ Standard } & & & Upper & Lower & Upper \\
& Coefficients & \multicolumn{1}{c}{ Error } & \multicolumn{1}{c}{ Stat } & P-value & Lower 95\% & \multicolumn{1}{c}{$95 \%$} & \multicolumn{1}{c}{$95.0 \%$} & $95.0 \%$ \\
\hline Intercept & 103.3413 & 19.54789 & 5.286568 & $9.13522 \mathrm{E}-05$ & 61.67591 & 145.0066 & 61.67591 & 145.0066 \\
Heating EUI & 0.794771 & 0.116763 & 6.80671 & $5.92494 \mathrm{E}-06$ & 0.545897 & 1.043645 & 0.545897 & 1.043645 \\
Cooling EUI & -0.01404 & 0.25291 & -0.05553 & 0.95644867 & -0.55311 & 0.525021 & -0.55311 & 0.525021 \\
Base Load EUI & 0.741899 & 0.140802 & 5.269094 & $9.44411 \mathrm{E}-05$ & 0.441787 & 1.042012 & 0.441787 & 1.042012 \\
\hline
\end{tabular}




\section{References}

Binkley, C., Touchie, M. F., \& Pressnail, K. D. (2012). Energy Consumption Trends of Multi-Unit Residential Buildings in the City of Toronto. University of Toronto.

Brown, C., \& Gorgolewski, M. (2014). Assessing occupant satisfaction and energy behaviours in Toronto's LEED gold high-rise residential buildings. International Journal of Energy Sector Management, 8(4), 492-505. https://doi.org/10.1108/IJESM-11-2013-0007

Brown, C., Gorgolewski, M., \& Goodwill, A. (2015). Using physical, behavioral, and demographic variables to explain suite-level energy use in multiresidential buildings. Building and Environment, 89, 308-317. https://doi.org/10.1016/j.buildenv.2015.02.039

Brown, C., Turcato, A., \& Gorgolewski, M. (2015). Best Practice Guide: Methodology and Results for Energy and Water Benchmarking. Toronto, ON.

Canada Green Building Council. (2004). LEED Canada-NC 1.0 Reference Guide (pp. 159-254).

Canada Green Building Council. (2017). LEED: The International Mark of Excellence. Retrieved from

https://www.cagbc.org/CAGBC/LEED/CAGBC/Programs/LEED/_LEED.aspx?hkey=54c447 92-442b-450a-a286-4aa710bf5c64

Chance, S. (2012). Planning for Environmental Sustainability Learning from LEED and the USGBC. Planning for Higher Education, 41(1), 194-234. https://doi.org/10.21427/D7GS5C

Chokor, A. (2015). Evaluating the Performance of Leadership in Energy and Environmental Design ( LEED ) Certified Facilities using Data-Driven Predictive Models for Energy and Occupant Satisfaction with Indoor Environmental Quality ( IEQ ) by Abbas Chokor A Thesis Presented, (November). 
Cropp, J., Lee, A., Castor, C. S., \& Energy Trust of Oregon. (2014). Evaluating Results for LEED Buildings in an Energy Efficiency Program. ACEEE Summer Study on Energy Efficiency in Buildings, 3(USGBC 2014), 63-74.

Fedoruk, L. E., Cole, R. J., Robinson, J. B., \& Cayuela, A. (2015). Learning from failure: understanding the anticipated-achieved building energy performance gap. Building Research \& Information, 43(6), 750-763. https://doi.org/10.1080/09613218.2015.1036227

Government of Canada. (n.d.). Canadian Climate Normals 1981-2010 Station Data. Retrieved from http://climate.weather.gc.ca/climate_normals/results_1981_2010_e.html?searchType=stnN ame\&txtStationName=Tor\&searchMethod=contains\&txtCentralLatMin=0\&txtCentralLatSec $=0 \&$ txtCentralLongMin $=0 \&$ txtCentralLongSec $=0 \& \operatorname{stn} \mid \mathrm{D}=5051$ \&dispBack $=0$

Huang, Y. (2012). Energy Benchmarking and Energy Saving Assessment in High-Rise MultiUnit Residential Buildings. Ryerson University.

Menezes, A. C., Cripps, A., Bouchlaghem, D., \& Buswell, R. (2012). Predicted vs. actual energy performance of non-domestic buildings: Using post-occupancy evaluation data to reduce the performance gap. Applied Energy, 97, 355-364. https://doi.org/10.1016/j.apenergy.2011.11.075

Scofield, J. H. (2013). Efficacy on LEED-certification in reducing energy consumption and greenhouse gas emissions for large New York City office buildings. Energy and Buildings, 67, 517-524. https://doi.org/10.1016/j.enbuild.2013.08.032

Straube, J. F., \& Burnett, E. F. P. (2005). Building Science for Building Enclosures. Westford, MA: Building Science Press.

Turner, C., \& Frankel, M. (2008). Energy Performance of LEED ® for New Construction 
Buildings. New Buildings Institute, 1-46. 